\title{
Detailed modeling of mountain wave PSCs
}

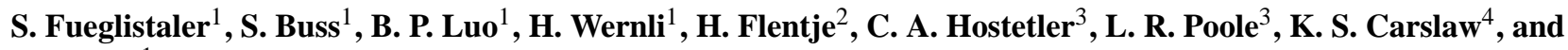 \\ Th. Peter ${ }^{1}$ \\ ${ }^{1}$ Atmospheric and Climate Science, ETH Zürich, Switzerland \\ ${ }^{2}$ DLR Oberpfaffenhofen, 82230 Wessling, Germany \\ ${ }^{3}$ NASA Langley Research Center, Hampton, VA, USA \\ ${ }^{4}$ School of the Environment, Univ. of Leeds, Leeds, UK
}

Received: 6 November 2002 - Published in Atmos. Chem. Phys. Discuss.: 13 January 2003

Revised: 3 June 2003 - Accepted: 4 June 2003 - Published: 11 June 2003

\begin{abstract}
Polar stratospheric clouds (PSCs) play a key role in polar ozone depletion. In the Arctic, PSCs can occur on the mesoscale due to orographically induced gravity waves. Here we present a detailed study of a mountain wave PSC event on 25-27 January 2000 over Scandinavia. The mountain wave PSCs were intensively observed by in-situ and remote-sensing techniques during the second phase of the SOLVE/THESEO-2000 Arctic campaign. We use these excellent data of PSC observations on 3 successive days to analyze the PSCs and to perform a detailed comparison with modeled clouds. We simulated the 3-dimensional PSC structure on all 3 days with a mesoscale numerical weather prediction (NWP) model and a microphysical box model (using best available nucleation rates for ice and nitric acid trihydrate particles). We show that the combined mesoscale/microphysical model is capable of reproducing the PSC measurements within the uncertainty of data interpretation with respect to spatial dimensions, temporal development and microphysical properties, without manipulating temperatures or using other tuning parameters. In contrast, microphysical modeling based upon coarser scale global NWP data, e.g. current ECMWF analysis data, cannot reproduce observations, in particular the occurrence of ice and nitric acid trihydrate clouds. Combined mesoscale/microphysical modeling may be used for detailed a posteriori PSC analysis and for future Arctic campaign flight and mission planning. The fact that remote sensing alone cannot further constrain model results due to uncertainities in the interpretation of measurements, underlines the need for synchronous in-situ PSC observations in campaigns.
\end{abstract}

Correspondence to: S. Fueglistaler

(stefanf@atmos.umnw.ethz.ch)

\section{Introduction}

Polar stratospheric clouds (PSCs) play a key role in polar ozone depletion. On the aerosol surface, heterogeneous chemical reactions take place that activate chlorine from inert reservoir species $\left(\mathrm{ClONO}_{2}, \mathrm{HCl}\right)$ to $\mathrm{Cl}_{2}$, which is rapidly photolyzed into atomic chlorine radicals (Solomon et al., 1986; Tolbert et al., 1987):

$\mathrm{ClONO}_{2}+\mathrm{HCl} \longrightarrow \mathrm{Cl}_{2}+\mathrm{HNO}_{3}$

and

$\mathrm{HCl}+\mathrm{HOCl} \longrightarrow \mathrm{Cl}_{2}+\mathrm{H}_{2} \mathrm{O}$

$\mathrm{Cl}_{2}+\mathrm{h} v \longrightarrow \mathrm{Cl}+\mathrm{Cl}$

The chlorine radicals then destroy ozone in catalytic cycles (Molina and Molina , 1987; McElroy et al., 1986).

In addition, PSCs can permanently remove $\mathrm{HNO}_{3}$ through sedimentation, a process termed denitrification, which slows the transfer of active chlorine into $\mathrm{CLONO}_{2}$ and hence further promotes ozone destruction (WMO, 1999; Waibel et al., 1999; Tabazadeh et al., 2000; Gao et al., 2001).

In contrast to Antarctica where a stable vortex prevails each winter, in the Arctic the vortex is less stable and synoptic temperatures remain often above the temperatures required for PSC formation. However, local mechanisms such as orographically induced gravity waves that propagate into the stratosphere can lead to adiabatic cooling (and warming). In the cold phases of these waves PSCs may form even though synoptic scale temperatures are too high. These so-called mountain wave PSCs are located in the coldest regions over and in the lee of mountains, and often are quasistationary (i.e. change slowly compared with the time-scale given by the passage of the air through the region where temperatures allow PSC formation). Repeated occurrence of mountain wave PSCs can "process" a significant fraction of 
the air in the polar vortex, despite their relatively small spatial dimension (Carslaw et al., 1998b).

Based on lidar observations by Browell et al. (1990), Toon et al. (1990) identified three distinct types of PSCs. Type 1a and $1 \mathrm{~b}$ both show low to moderate backscatter ratios (BSR). In contrast to type $1 \mathrm{~b}$ which was later identified as supercooled ternary $\left(\mathrm{HNO}_{3} / \mathrm{H}_{2} \mathrm{SO}_{4} / \mathrm{H}_{2} \mathrm{O}\right)$ solution (STS) droplets with number densities $\sim 10 \mathrm{~cm}^{-3}$ (Carslaw et al., 1994), type 1a shows moderate aerosol depolarization $\left(\delta_{\text {aerosol }}\right)$, which Biele et al. (2001) interpreted as containing small number densities $\left(n \lesssim 10^{-2} \mathrm{~cm}^{-3}\right.$ ) of aspherical particles, most likely nitric acid trihydrate (NAT). Type 2 PSCs show high BSRs and moderate to high depolarisation, attributed to water ice particles. Later, Tsias et al. (1999) identified type 1a-enh PSCs as similar to type 1a but with enhanced NAT particle number densities $\left(n \gtrsim 0.1 \mathrm{~cm}^{-3}\right)$. First evidence from in-situ measurements for the presence of NAT particles in PSCs was given by Voigt et al. (2000) from a balloonborne experiment during the SOLVE/THESEO-2000 campaign. During the same campaign, Fahey et al. (2001) detected for the first time very large $\mathrm{HNO}_{3}$-containing (presumably NAT) particles in very low number densities (so-called "NAT-rocks") which can efficiently denitrify the polar stratosphere. Apart from ternary solution droplets and NAT the existence of other $\mathrm{HNO}_{3}$ containing hydrates, such as nitric acid dihydrate (NAD), is also still under debate.

Carslaw et al. (1998a) and Wirth et al. (1999) successfully modeled lidar measurements of mountain wave PSCs from flights that were parallel to the wind direction (so-called quasi-Lagrangian measurements). They used a microphysical box model that calculated the PSC microphysics along a manually inferred trajectory, and without exact knowledge of ice or NAT nucleation rates. Using T-Matrix calculations for aspherical solid particles (Mishchenko , 1991) and Mie calculations with an index of refraction as a function of aerosol composition, temperature and wavelength for the liquid aerosol (Krieger et al., 2000), it was shown that the simulated lidar signal inferred from the modeled microphysics could be brought into good agreement with the observations, provided that the trajectory was chosen carefully and that the number densities of ice and NAT particles were chosen within plausible limits.

\section{Mesoscale/microphysical modeling approach}

Here we significantly improve the method of Carslaw et al. (1998a) and Wirth et al. (1999) and extend its scope. Instead of manually inferred trajectories we use trajectories from mesoscale numerical weather prediction (NWP) models. This greatly reduces the degrees of freedom of the model. Trajectories from NWP models furthermore allow us to simulate the 3-dimensional structure of PSCs, and allow predictions of PSC occurrences where no measurements are available. We use trajectories from the mesoscale High

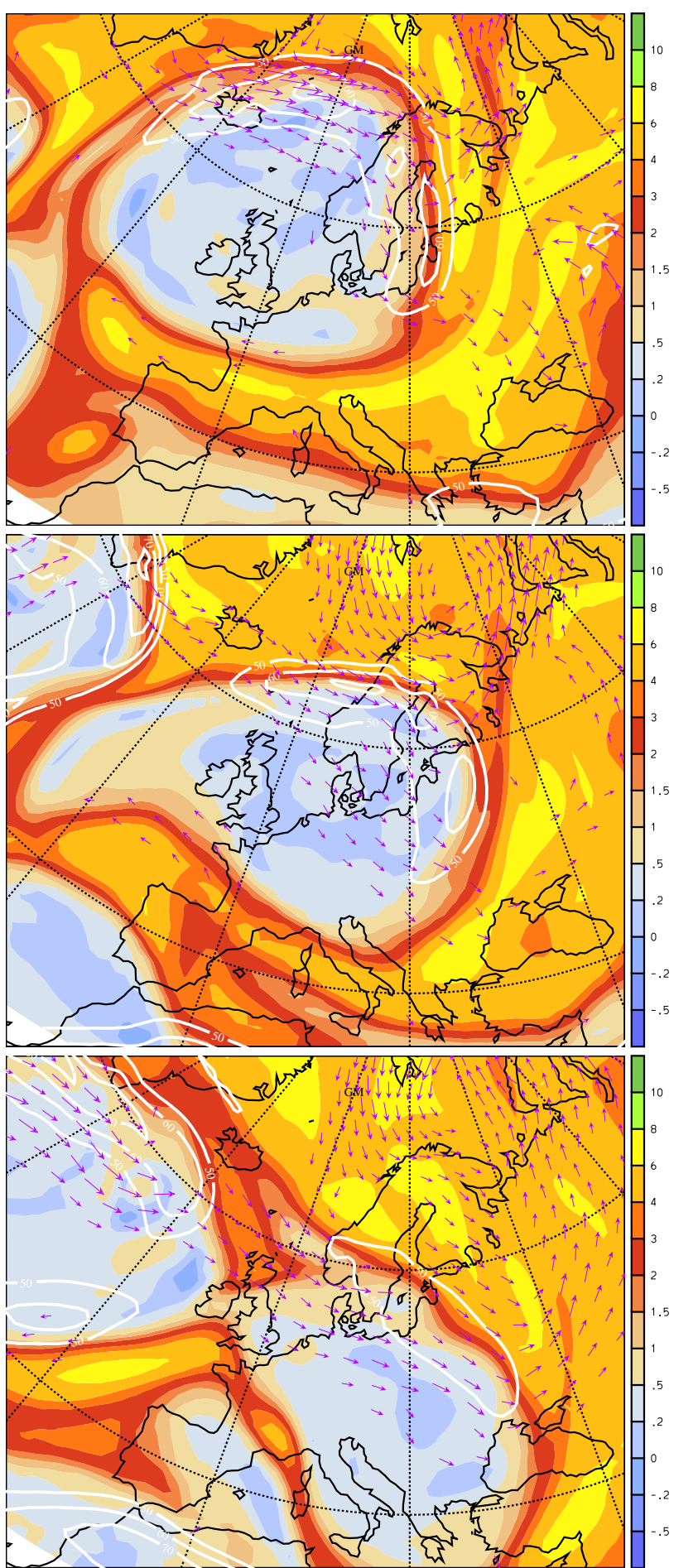

Fig. 1. The synoptic situation at 12:00 UTC, 25 January (top), 26 January (middle) and 27 January (bottom) from ECMWF analysis data. Color-coded: potential vorticity at $315 \mathrm{~K}$ (in pvu). White lines: wind speed at $250 \mathrm{hPa}$ (isolines for $50,60,70 \mathrm{~m} / \mathrm{s}$ ). Violet vectors: wind velocity field at $900 \mathrm{hPa}$ for windspeeds larger than $10 \mathrm{~m} / \mathrm{s}$. 
Resolution Model (HRM, cf. Sect. 3.5) and compare them with trajectories from ECMWF analysis data.

An updated version of the microphysical box model is used, which calculates the nucleation of ice and NAT particles. We use the nucleation rates given by Koop et al. (2000) for the homogeneous freezing of ice particles and those provided by Luo et al. (2002) for the NAT nucleation on ice surfaces exposed to the gas phase, instead of adjusting the solid particle number densities manually as was done by Carslaw et al. (1998a) and Wirth et al. (1999). The approach chosen in this study uses the current understanding of numerical weather prediction models and microphysical processes in a self-consistent way without any "tuning", such that the simulations can be run fully automatically. This enables to obtain the morphology of PSCs in 2-D or 3-D calculations instead of focusing on one or two selected trajectories. We compare the results of these simulations to measurements allowing to judge the accuracy of the state-of-the-art modeling.

The combined mesoscale/microphysical model is applied to the period 25-27 January over Scandinavia. The data acquired in this period during the SOLVE/THESEO-2000 Arctic campaign provide probably the most complete collection of data of a mountain wave PSC event. For all three successive days the simulations were performed with exactly the same setup, showing the robustness of the approach.

\section{Data and tools}

\subsection{Synoptic situation, 25-27 January 2000}

The meteorological situation leading to the mountain wave PSCs on 25-27 January over Scandinavia was discussed by Dörnbrack et al. (2002). Figure 1 shows the potential vorticity (PV) field on the $345 \mathrm{~K}$ isentropic surface, wind speed in the upper troposphere $(250 \mathrm{hPa})$ and wind vectors in the lower troposphere $(900 \mathrm{hPa})$ for 25-27 January 2000. The isentropic PV charts are well suited, for instance, to identify large-scale upper-tropospheric anticyclones (characterized by PV values $<2$ pvu) and jet-stream regions (characterized by strong horizontal PV gradients).

In agreement with Doernbrack et al. we note for 25 January the existence of an extreme upper-level anticyclone over the UK, Iceland and Norway with strong low-level winds towards northern Norway and a northerly upper tropospheric jet over Scandinavia. In the course of the 3 days the anticyclone shifts southward and on 26 January a very strong jet is directly over central Scandinavia. The jet is almost parallel to strong near surface westerlies, which provides very favourable conditions for excitation and vertical propagation of mountain waves. On 27 January the anticyclone shifted further south, leaving relatively weak low- and upper-level winds over Scandinavia, except for the southernmost part with upper-level wind speeds $\sim 50 \mathrm{~m} / \mathrm{s}$.
Table 1. Overview of platforms and instruments 25-27 January 2000 .

${ }^{1}$ Total recording time; ${ }^{2}$ flight crossing Scandinavian mountain; ${ }^{3}$ flight not aligned to wind direction; ${ }^{4}$ lidar data shown in this study

\begin{tabular}{lll}
\hline Day & Plattform/Instrument & Time UTC \\
\hline 25 & DC-8/LaRC & $08: 48-17: 33^{1}$ \\
& & $13: 15-14: 34^{2}$ \\
& & $15: 03-15: 38^{2,4}$ \\
& & $16: 01-17: 13^{2}$ \\
& & $14: 05-16: 17$ \\
& Falcon/OLEX & $20: 30-22: 30$ \\
& Balloon/ACMS & \\
26 & Falcon/OLEX & $13: 17-16: 03^{1}$ \\
& & $13: 17-13: 41^{2}$ \\
& & $13: 41-13: 58^{3}$ \\
& & $13: 58-14: 51^{2,4}$ \\
27 & DC-8/LaRC & $09: 54-18: 41^{1}$ \\
& & $12: 53-13: 30^{3,4}$ \\
& & $13: 57-14: 33^{2}$ \\
& Falcon/OLEX & $13: 29-14: 33^{1}$ \\
& & $13: 36-13: 59^{2,4}$ \\
& ER-2 & $09: 00-15: 06$ \\
\hline
\end{tabular}

\subsection{PSC measurement}

In this study lidar data is used from the NASA LaRC Aerosol Lidar (a piggy-back instrument to the NASA GSFC AROTEL lidar, $532 \mathrm{~nm}, 1064 \mathrm{~nm}$ ) on board the NASA DC-8 aircraft and the DLR OLEX lidar system (354 nm, $532 \mathrm{~nm}$, $1064 \mathrm{~nm}$ ) on board the Falcon aircraft (Flentje et al., 1999). Both systems measure total backscatter at all wavelengths and depolarization at $532 \mathrm{~nm}$, which allows discrimination of spherical (STS) and aspherical (e.g. NAT and ice) particles. In addition, we will refer to the results of the balloonborne measurements of 25 January (Voigt et al., 2000) and the in-situ measurements on board the stratospheric research aircraft ER-2 on 27 January (Northway et al., 2002). Table 1 provides an overview of the platforms in operation on 2527 January and from the data used in this study. The data is analyzed in Sect. 4.

\subsection{Analysis of lidar data}

A lidar system emits a laser pulse and measures the backscatter from aerosols and air molecules as a function of time. The backscatter ratio BSR is defined as

$B S R=1+\frac{\beta^{\text {aerosol }}}{\beta^{\text {air }}}$,

where $\beta^{\text {aerosol }}$ is the backscatter coefficient of aerosol and $\beta^{a i r}$ is the backscatter coefficient of air molecules (Rayleighscattering). The lidar system measures the total backscatter 


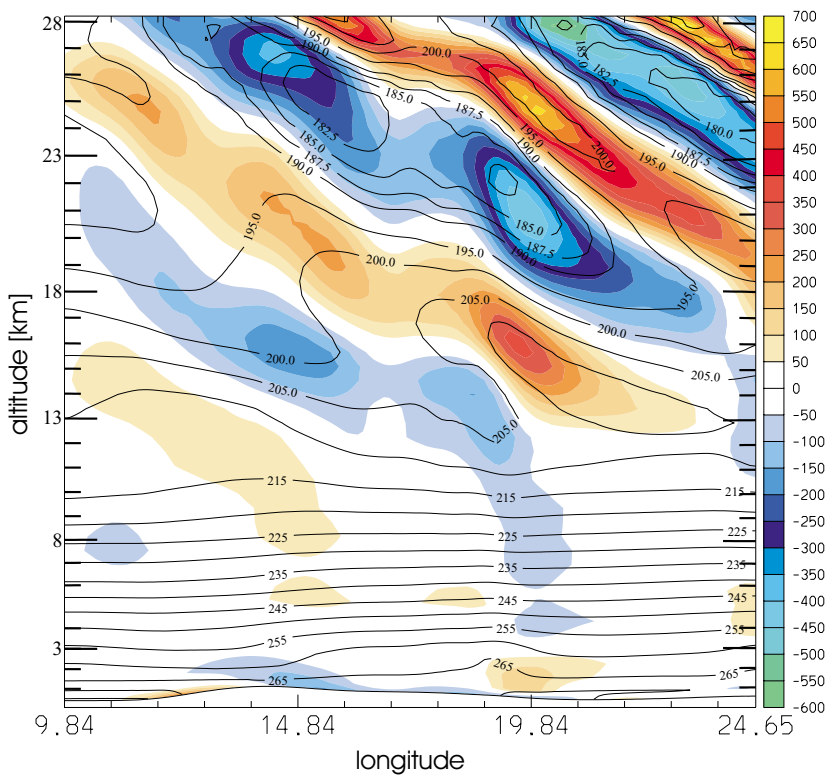

Fig. 2. West-east cross-section of HRM simulation, 15:00 UTC, 26 January 2000, along flight path of Falcon aircraft (leg 3, see Fig. 6). Color coded: horizontal divergence (blue) and convergence (red) of wind field $\left[10^{6} \mathrm{~s}^{-1}\right]$. Black solid lines: temperature $[\mathrm{K}]$, lowermost line shows the orography.

coefficient $\beta^{\text {total }}=\beta^{\text {aerosol }}+\beta^{\text {air }}$, and in order to obtain the backscatter ratio, the backscatter coefficient $\beta^{\text {air }}$ has to be calculated as a function of air density. The depolarization of the scattered laser pulse yields information about the shape of the scatterer. The aerosol depolarization is defined as:

$\delta^{\text {aerosol }}=\frac{\beta_{\perp}^{\text {aerosol }}}{\beta_{\|}^{\text {aerosol }}}$

where $\beta_{\perp}^{\text {aerosol }}$ is the perpendicular aerosol backscatter coefficient and $\beta_{\|}^{\text {aerosol }}$ is the parallel aerosol backscatter coefficient. The color ratio is defined as the ratio of the aerosol backscattering coefficient at two wavelengths $\lambda_{1}, \lambda_{2}$ with $\lambda_{1}<\lambda_{2}$ :

$C R\left(\lambda_{1} / \lambda_{2}\right)=\frac{\beta_{\lambda_{1}}^{\text {aerosol }}}{\beta_{\lambda_{2}}^{\text {aerosol }}}$

The color ratio is very sensitive to the size of the scatterers, but independent of the number of scatterers. We will use the following notation: the backscatter ratio at $1064 \mathrm{~nm} \equiv \mathrm{BSR}(1064)$, the color ratio $\beta_{532}^{\text {aerosol }} / \beta_{1064}^{\text {aerosol }} \equiv$ $\mathrm{CR}(532 / 1064)$, and the aerosol depolarization at $532 \mathrm{~nm} \equiv$ $\delta^{\text {aer }}(532)$.

Based on long term lidar observations over Ny Alesund, Spitsbergen $\left(78.9^{\circ} \mathrm{N}, 11.9^{\circ} \mathrm{E}\right)$ and T-Matrix calculations, Biele et al. (2001) presented a classification of lidar data. They classify PSCs into the following types: type 1a (aspherical particles, most likely NAT, low particle number densities $n \approx 10^{-2} \mathrm{~cm}^{-3}$ ), type 1a-enh (aspherical particles, most likely NAT, high particle number densities $n \gtrsim 0.1 \mathrm{~cm}^{-3}$ ), type $1 \mathrm{~b}$ (ternary $\mathrm{HNO}_{3} / \mathrm{H}_{2} \mathrm{SO}_{4} / \mathrm{H}_{2} \mathrm{O}$ aerosol droplets (STS), $n \approx 10 \mathrm{~cm}^{-3}$ ), type mix (spherical and aspherical particles, likely NAT and STS particles mixed externally and not in thermodynamic equilibrium) and type 2 (ice particles, $n=1$ $10 \mathrm{~cm}^{-3}$ ). We will use this classification as a reference in our lidar data interpretation.

The backscatter of aspherical particles may be calculated using the T-Matrix method (Mishchenko , 1991) (with spheroids of aspect ratio $0.5-1.5$ as proxies for ice and NAT particles). The index of refraction is 1.31 for ice and 1.48 for NAT (Middlebrook et al., 1994; Toon et al., 1994), that of STS obtained from Krieger et al. (2000).

\subsection{Microphysical modeling}

A microphysical box model is used to calculate the evolution of the aerosol along a trajectory. The thermodynamics governing the condensation/evaporation kinetics of water and nitric acid by the aqueous sulfuric acid aerosol is calculated from an ion-interaction model (Pitzer , 1991; Luo et al., 1995; Meilinger et al., 1995). The aerosol size distribution is assumed to be log-normal with an initial mode radius of $0.06 \mu \mathrm{m}$ and a mode width of 1.6 at $T=210 \mathrm{~K}$. All calculations were performed with $n=13 \mathrm{~cm}^{-3}$ background aerosol particles, the sensitvity of the model results on background aerosol number density being small. The size distribution is modeled using 26 size bins for the liquid aerosol. Homogeneous ice nuleation in STS droplets is calculated from the nucleation rates by Koop et al. (2000), and the ice vapor pressure is calculated in accordance with Marti and Mauersberger (1993). NAT nucleation on exposed ice surfaces is calculated in accordance with Luo et al. (2002), and the NAT vapor pressure is taken from Hanson and Mauersberger (1988). For each timestep, the number of nucleating ice and NAT particles is calculated for each size bin and transferred to new bins of their own. Upon evaporation of ice and NAT particles, the resulting droplets return into their original size bin.

The water mixing ratio in the Arctic stratosphere is taken from a linear interpolation of measured water mixing ratios on 27 January 2000 with a mixing ratio $\chi_{\mathrm{H} 2 \mathrm{O}}=4.2 \mathrm{ppmv}$ at $400 \mathrm{~K}$ and $\chi_{\mathrm{H} 2 \mathrm{O}}=6.3 \mathrm{ppmv}$ at $600 \mathrm{~K}$ (Schiller et al., 2002). In agreement with Arctic mid-winter measurements (Kleinböhl et al., 2003), an $\mathrm{HNO}_{3}$ profile with constant volume mixing ratio of $7.5 \mathrm{ppmv}$ is used (altitude-dependent deviations in the order of $30 \%$ may be expected in a real profile, but do not significantly alter model results).

\subsection{Mesoscale modeling}

Mesoscale numerical modeling studies (that include validation with observations) of gravity waves over Scandinavia that propagate into the stratosphere and lead to wave-induced PSCs were performed previously by Dörnbrack et al. (1999, 
2001). Furthermore, Dörnbrack et al. (2002) modeled 2527 January 2000 episode with the mesoscale MM5 model. Here we calculated a series of mesoscale simulations with the High Resolution Model (HRM) (Majewski et al., 1991). A former version of this limited-area model was used operationally by the German and Swiss Weather Services until early 2001 and is widely used in the hindcast mode for regional climate simulations (e.g. Lüthi et al., 1996). The model integrates the set of primitive equations in the hydrostatic limit. The initial and boundary conditions are taken from ECMWF analyses, and a radiative upper boundary condition prevents wave reflection. We use a dry physics version of the model without radiation and a horizontal resolution of $0.125^{\circ}$ (corresponding to $\sim 14 \mathrm{~km}$ ) and 60 vertical levels up to $4 \mathrm{hPa}$ (regularly spaced in $\log p$ ). Further details of the model setup can be found in Buss et al. (A gravity wave induced ice cloud over Greenland: Model validation and investigation of dynamical mechanisms, manuscript in preparation). Sensitivity studies showed that the simulation of the gravity wave and the associated temperature fields is sensitive to horizontal and vertical resolution and the initialization time, but insensitive to the height of the uppermost model level as well as inclusion of radiatation and moisture. For the simulations presented here, the orography was lowpass filtered with a conservative diffusion operator in order to eliminate the grid-scale components of the gravity wave. The simulations were started every 24 hours for integration periods of 36 hours. The first 12 hours of each simulation were discarded before starting trajectory calculations (i.e. trajectories were calculated in the time window 12-36 hours of each simulation)

Figure 2 shows a vertical cross-section of the HRM simulation at 15:00 UTC, 26 January. The propagating gravity wave becomes evident from the tilted bands of horizontal divergence and convergence whose amplitude increases with height. The superimposed temperature field reveals two regions with temperatures below $185 \mathrm{~K}$ at $21-27 \mathrm{~km}$ altitude, in agreement with the location of PSCs (data shown below).

\section{Classification of lidar data}

Figure 3 shows an overview of the lidar measurements on 25-27 January. The lidar data was classified with the classification of Biele et al. (2001) and shows PSCs over Scandinavia on all 3 successive days. Figure 4 shows the flight path of the selected lidar data segments, and Fig. 5 shows the results of the classification of these data segments according to Biele et al. (2001).

\subsection{January 2000}

The DC- 8 crossed the Scandinavian mountain ridge three times, and on each crossing PSCs were observed, consisting of ice, STS, and likely NAT (see Fig. 3). The LaRC lidar
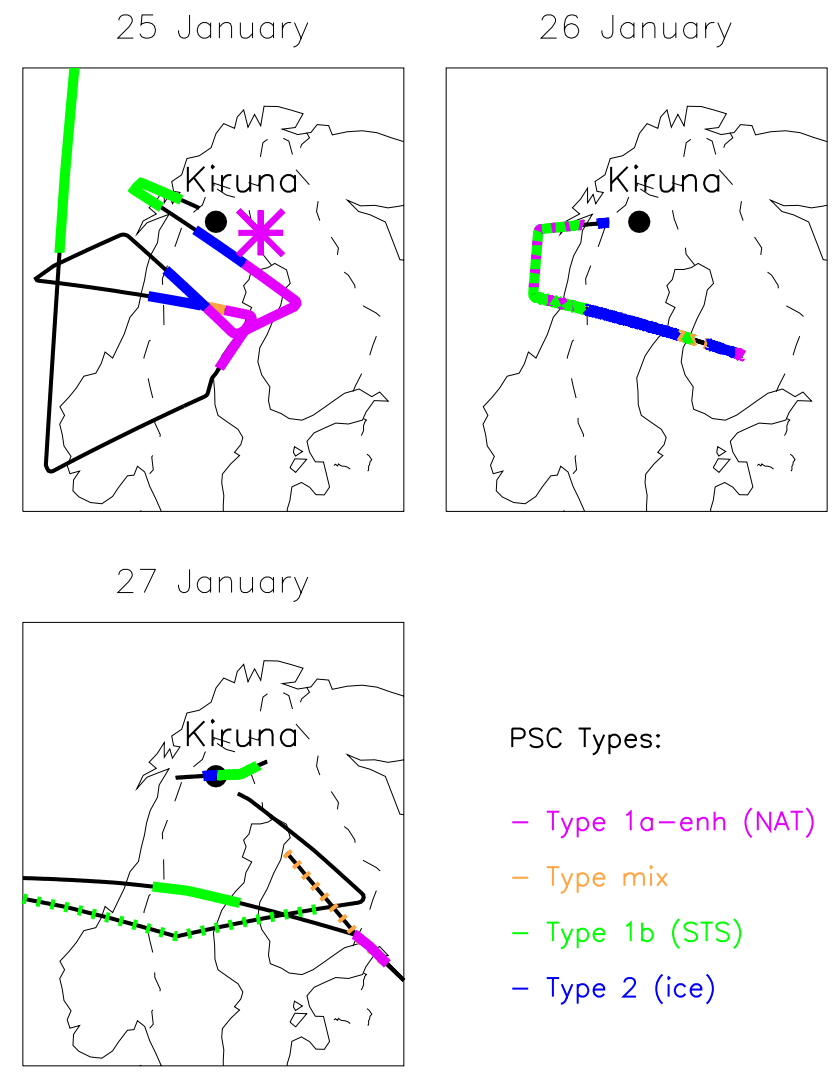

Fig. 3. Overview of lidar data 25-27 January 2000, classification according to Biele et al. (2001). Black lines show flight path without PSC observations, colored lines show flight path with PSC observations (color codes as indicated, dashed line segments indicate small PSC patches and/or two PSC types at the same position). 25 January: LaRC (NASA) lidar data, “*” indicates balloon-borne measurements of Voigt et al. (2000). 26 January: OLEX (DLR) lidar data. 27 January: LaRC (NASA) and OLEX (DLR) lidar data.

measurement between 15:03 UTC and 15:38 UTC (Figs. 3 and 5a) are representative for all lidar observations over Scandinavia on this day. The classification shows a large ice cloud over the Scandinavian mountain ridge, followed downstream by a type "mix" cloud and finally a type 1a-enh PSC. This sequence of PSC type has been observed before [eg. Carslaw et al. (1998a); Wirth et al. (1999)] and is interpreted as follows. As the air approaches the mountain ridge, it is rapidly lifted and adiabatically cooled. When temperatures reach the necessary supercooling of $\sim 3 \mathrm{~K}$, ice nuleation begins, leading to ice PSCs with high particle number densities due to the high cooling rates $(\sim 30 \mathrm{~K} / \mathrm{h})$. Very rapid cooling also prevents the background aerosol from taking up $\mathrm{HNO}_{3}$ before ice nucleation sets in, and the liquid aerosol droplets are initially out of thermodynamic equilibrium with the gas phase. Only during the evolution of the ice cloud, the liquid takes up $\mathrm{HNO}_{3}$ and depletes the gas phase. Behind the ridge the air sinks back to its original altitude, the temperature rises 


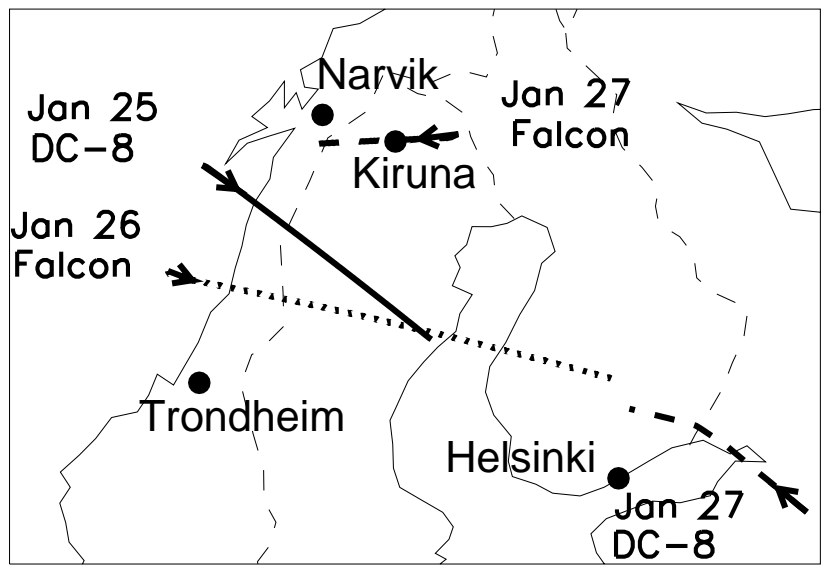

Fig. 4. Flight path segments of lidar data presented in this study, arrows indicate flight direction. Solid line: DC-8, 25 January 2000, 15:03-15:38 UTC; dotted line: Falcon, 26 January 2000, 13:5814:51 UTC (flight leg 3); dashed line: Falcon, 27 January 2000, 13:36-13:59 UTC and DC-8, 27 January 2000, 12:53-13:30 UTC.

and the ice particles evaporate. Depending on temperature, also the liquid ternary solution droplets evaporate $\mathrm{HNO}_{3}$ and develop back to binary $\mathrm{H}_{2} \mathrm{SO}_{4} / \mathrm{H}_{2} \mathrm{O}$ droplets. Eventually, the NAT particles evaporate when the temperature rises above the existence temperature $T_{\mathrm{NAT}}$, which is about $8 \mathrm{~K}$ above $T_{\text {ice }}$ (Hanson and Mauersberger, 1988). Zondlo et al. (2000) provide a comprehensive overview over these processes.

Based on the LaRC lidar data, Hu et al. (2002) estimated ice particle number densities in this PSC $n_{\text {ice }}=2-5 \mathrm{~cm}^{-3}$ with a mode radius $r=1.2-2 \mu \mathrm{m}$. NAT particle number densities were estimated as $n_{\mathrm{NAT}}=0.1-0.5 \mathrm{~cm}^{-3}$ with a mode radius $r=0.4-1 \mu \mathrm{m}$, in general agreement with our analysis (not shown). Balloon-borne in-situ measurements on this day at 20:30-22:30 UTC (see Fig. 3) show the presence of STS and NAT particles downwind of the Scandinavian mountain ridge at altitudes $22-23 \mathrm{~km}$, with a NAT particle number density of $n \approx 0.1 \mathrm{~cm}^{-3}$ and a radius $r=0.5-1 \mu \mathrm{m}$ (Voigt et al., 2000).

\subsection{January 2000}

Lidar observations on board of the Falcon aircraft show the presence of large ice PSCs over Scandinavia and patches of STS and type 1a-enh PSCs over the Atlantic ocean. Downstream of the large ice cloud over Scandinavia (see Fig. 5b, at $200-600 \mathrm{~km}$, and Fig. 3) the Falcon observed a second ice PSC over Finland (see Fig. 5b, at 750-850 km, and Fig. 3). This rather unique observation of 2 large successive PSCs was chosen as a test case for the combined mesoscale/microphysical modeling approach (Sect. 5). The first ice PSC was also observed by ground-based FTIR, and based on the FTIR data, Hoepfner et al. (2001) estimated the average ice particle number densities $n_{\text {ice }}=2-5 \mathrm{~cm}^{-3}$, with a corresponding particle radius $r=2-1 \mu \mathrm{m}$, in general
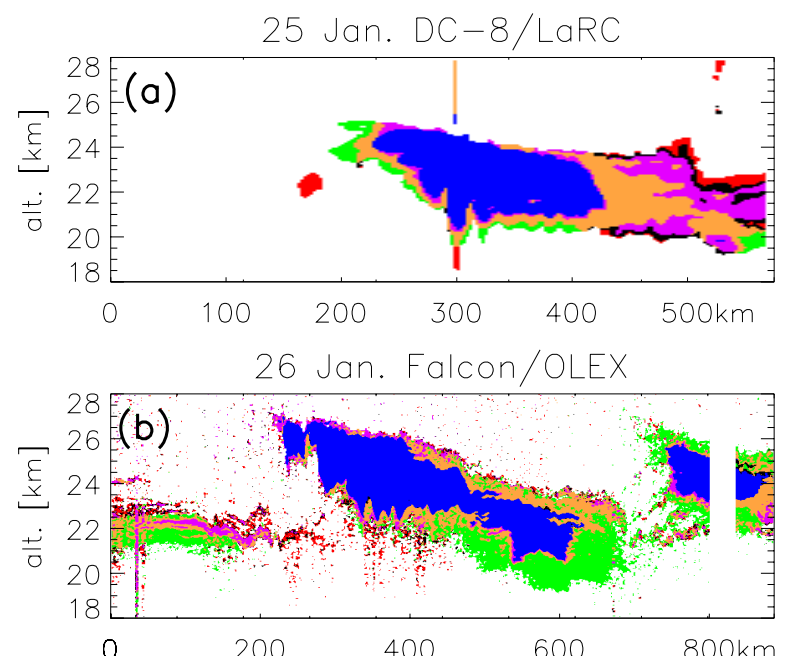

27 Jan. Falcon/OLEX 27 Jan. DC-8/LaRC
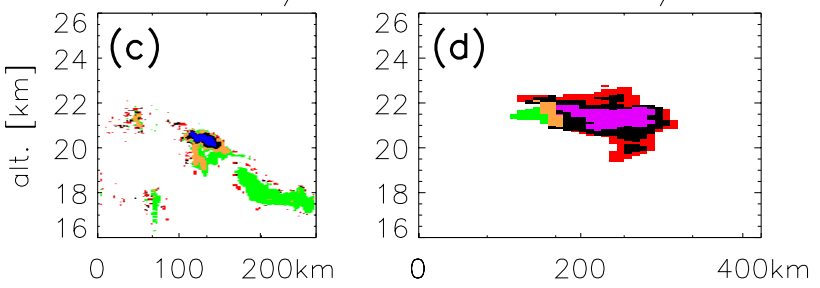

* Type 1 a (NAT)

* Type $1 \mathrm{a}$-enh (NAT) * Type 1 b (STS) * Type 2 (Ice)

Fig. 5. Classification of lidar data according to Biele et al. (2001). Color codes as indicated, black areas cannot be assigned to a class. Wind direction from left to right, except panel (d) with perpendicular wind. (a) Classification of LaRC lidar observation on board the NASA DC-8 aircraft, 25 January 2000, 15:03-15:38 UTC. (b) Classification of OLEX lidar data on board the DLR Falcon aircraft, 26 January 2000, 13:58-14:51 UTC. (c) Classification of OLEX lidar data, 27 January 2000, 13:36-13:59 UTC. (d) Classification of LaRC lidar data, 27 January 2000, 12:53-13:30 UTC. Data segments correspond to flight paths in Fig. 2.

agreement with the analysis presented in Sect. 5. Directly downstream of the first ice PSC, following a small region of type "mix", only a tiny margin of the PSC is identified as type 1a/1a-enh (see Fig. 5 b, at $300-650 \mathrm{~km}$ and $22-26 \mathrm{~km}$ alt.). A few isolated NAT "streaks" leave the lower part of the first ice cloud (see Fig. $5 \mathrm{~b}$ at $\sim 700 \mathrm{~km}$ ). The PSC upstream of the first ice cloud (see Fig. 5b, at 0-200 km, altitude $\approx 22 \mathrm{~km}$ ) is classified as 1a-enh/mix/STS and is part of several stratified PSC patches observed at $\approx 22 \mathrm{~km}$ altitude over the Atlantic (see Fig. 3).

The second ice cloud shows a clearer type 1a-enh signal downstream. Unfortunately, the aircraft turned northward (and hence the subsequent flight leg is not quasi-Lagrangian) just when the type 1a-enh signal appears (see right edge of Fig. 5b). The classification of STS below the second ice cloud indicates that NAT particles (originating from the first 
ice cloud), if present at all, must be small $(r<0.5 \mu \mathrm{m})$ and in very low number densities $n_{\mathrm{NAT}} \approx 0.01 \mathrm{~cm}^{-3}$, such that the liquid droplets dominate the lidar backscatter.

\subsection{January 2000}

On 27 January PSCs were sparse compared to the two preceding days. At 13:45 UTC the Falcon observed a small $(\approx$ $30 \mathrm{~km}$ in wind direction) ice PSC near Kiruna, about $50 \mathrm{~km}$ downstream of Kebnekaise, the highest peak in northern Scandinavia $\left(18^{\circ} 33^{\prime} \mathrm{E} / 67^{\circ} 53^{\prime} \mathrm{N}\right.$, elevation $\left.2111 \mathrm{~m}\right)$. Downstream of and just below the ice PSC there is STS (see Figs. 3 and $5 \mathrm{c}$ ). The small geographical dimensions of the cloud indicates that in general temperatures were above the ice nucleation temperature, but single mountains such as Kebnekaise may generate gravity waves of small horizontal dimensions and thus localized cooling.

The DC- 8 headed south from Kiruna and observed a PSC near Helsinki/St.Petersburg (13:00-13:15 UTC, Figs. 3 and $5 \mathrm{~d})$. On the subsequent crossing of the mountain ridge, only STS was observed. The cloud near Helsinki classifies as type 1a-enh, type 1a and a small section as type $1 \mathrm{~b}$ (STS). A hypothesis for the genesis of this NAT cloud will be presented in Sect. 6.

In addition to the lidar data, in-situ measurements on board the NASA ER-2 stratospheric research aircraft are available for this day. The ER-2 left Kiruna at $\sim$ 09:00 UTC and headed south over Finland towards Russia, from where it returned to Kiruna. During the entire flight, the $\mathrm{NO}_{\mathrm{y}}$ instrument found particulate matter at two positions only: on the outbound flight at $\sim 10: 00 \mathrm{UTC}, 27.83^{\circ} \mathrm{E} / 61.44^{\circ} \mathrm{N}$, and on the incoming flight at $\sim 13: 15 \mathrm{UTC}, 29.45^{\circ} \mathrm{E} / 59.9^{\circ} \mathrm{N}$. The two locations are in agreement with the lidar observation of the type 1a-enh PSC discussed above. Based on the $\mathrm{NO}_{\mathrm{y}}$ data, Northway et al. (2002) estimated a particle radius $r \approx 3 \mu \mathrm{m}$ (outgoing flight leg) and $r \approx 4 \mu \mathrm{m}$ (incoming flight leg) in low number densities $n_{\mathrm{NAT}} \approx 3 \times 10^{-4} \mathrm{~cm}^{-3}$. T-Matrix calculations for NAT particles of these sizes and number densities yield a backscatter ratio $\operatorname{BSR}(1064) \lesssim 1.25$, which is far from the observed values $\operatorname{BSR}(1064) \approx 3-15$. The observed color ratio $\mathrm{CR}(532 / 1064) \approx 1.1-3$ of the lidar observation indicates that the cloud mainly consists of smaller particles (from T-Matrix calculations we estimate $r \approx 0.8 \mu \mathrm{m}, n_{\mathrm{NAT}} \approx 0.3 \mathrm{~cm}^{-3}$, corresponding to $\sim 3 \mathrm{ppmv}$ $\mathrm{HNO}_{3}$ in the solid phase). This discrepancy between in-situ $\mathrm{NO}_{\mathrm{y}}$ and lidar data may be resolved by the fact that the altitude of the ER-2 measurement $(\sim 20 \mathrm{~km})$ is at the extreme bottom of the PSC observed by the lidar (see Fig. 5d). It can be speculated whether these larger particles at the cloud bottom result from sedimentation processes as proposed by Fueglistaler et al. (2002a); Dhaniyala et al. (2002). In addition, the NAT number densities at the edges of the cloud may be smaller due to less favorable nucleation conditions at cloud formation time. Both processes can lead to the observed low number density. In sum we may conclude that

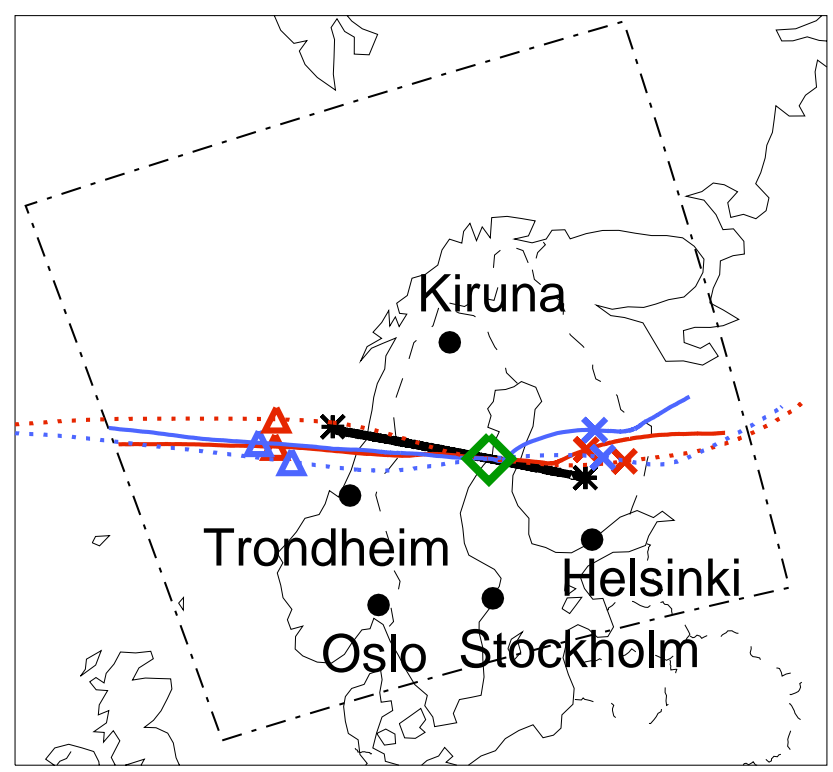

Fig. 6. Falcon flight path and air parcel trajectories on 26 January 2000, and domain boundaries of the mesoscale model HRM (black dash-dotted lines). Black solid line: Falcon flight path (leg 3, flight direction from west to east, 13:58-14:51 UTC). Colored lines: isentropic forward and backward trajectories on $500 \mathrm{~K}$ (red) and $600 \mathrm{~K}$ (blue), started at $20.37^{\circ} \mathrm{E} / 63.75^{\circ} \mathrm{N}, 15: 00 \mathrm{UTC}$ (green diamond). Dotted lines: ECMWF trajectories. Solid lines: HRM trajectories. Wind direction from West to East, triangles indicate trajectory positions at 10:00 UTC, and crosses positions at 18:00 UTC.

this cloud consists of NAT particles with $r \lesssim 4 \mu \mathrm{m}$, most likely with $r \approx 0.8 \mu \mathrm{m}$ and $n_{\mathrm{NAT}} \approx 0.3 \mathrm{~cm}^{-3}$.

\section{Detailed PSC modeling, 26 January 2000}

A comprehensive microphysical box model (Luo et al., 2002) was used with trajectories from NWP models. Forward and backward trajectories were calculated starting at $20.37^{\circ} \mathrm{E} / 63.75^{\circ} \mathrm{N}, 15: 00 \mathrm{UTC}$ between $400 \mathrm{~K}$ and $650 \mathrm{~K}$ potential temperature in increments of $2 \mathrm{~K}$ (corresponding to a vertical resolution $\sim 100 \mathrm{~m}$, yielding a total of 126 trajectories), from both ECMWF analysis data and the HRM simulation.

Figure 6 shows the flight path of the Falcon on 26 January (flight leg 3, black), ECMWF and HRM trajectories at $500 \mathrm{~K}$ (red) and $600 \mathrm{~K}$ (blue) and the trajectory starting position (green). The figure shows that the flight path is quasiLagrangian (i.e. parallel to the wind direction) and consequently the microphysical calculations along these trajectories can be directly compared to the observations. Minor deviations between observations and calculated simulations should not come as a surprise, since flight path and trajectories are not perfectly aligned, and the mountain wave cannot be considered as strictly stationary. 

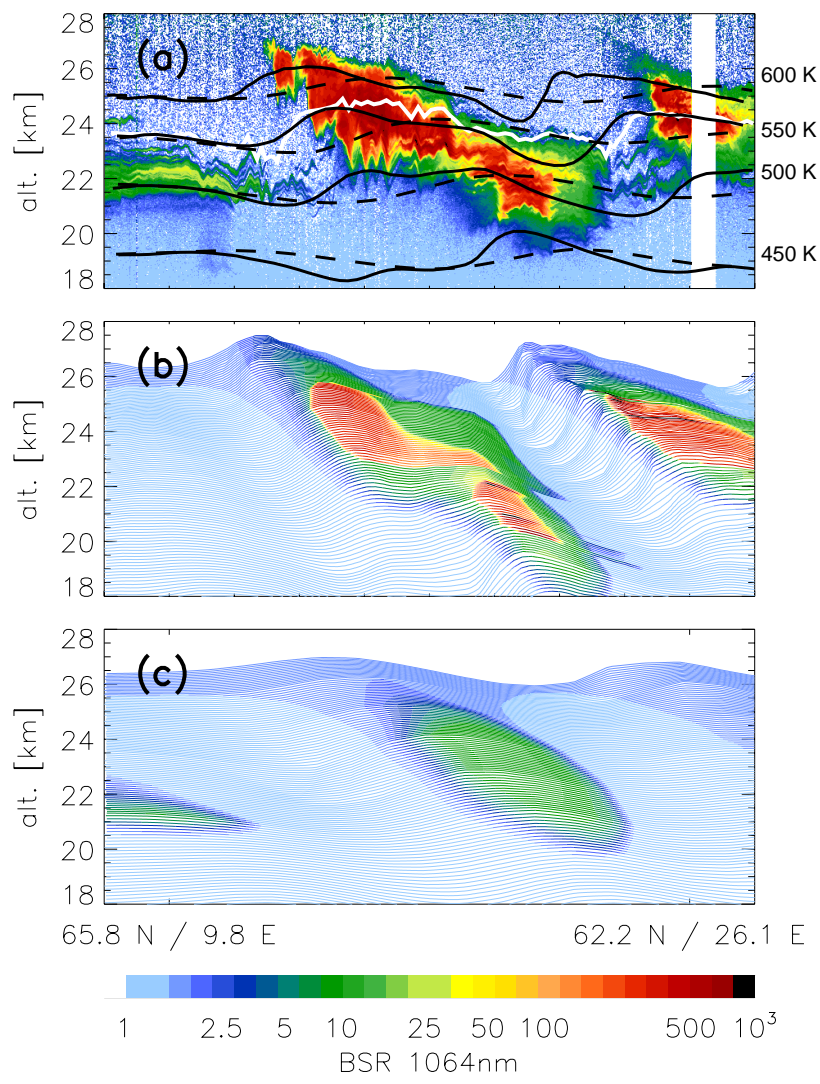

Fig. 7. (a) OLEX lidar data (BSR $1064 \mathrm{~nm}$ ), 26 January 2000, and selected trajectories calculated from ECMWF analysis data (black dashed lines) and the HRM simulation (black solid lines). White solid line: manually modified (based on the lidar image) HRM trajectory $(550 \mathrm{~K})$. Trajectories started at $20.37^{\circ} \mathrm{E} / 63.75^{\circ} \mathrm{N}$, 15:00 UTC on the labelled isentropes. (b) Lidar signal (BSR 1064 $\mathrm{nm}$ ) inferred from microphysical model calculations along the 126 trajectories between $400 \mathrm{~K}$ and $650 \mathrm{~K}$ calculated with the HRM mesoscale simulation. (c) Lidar signal (BSR $1064 \mathrm{~nm}$ ) inferred from microphysical model calculations along the 126 trajectories between $400 \mathrm{~K}$ and $650 \mathrm{~K}$ calculated with ECMWF analysis data.

The simulated backscatter ratio BSR(1064) based on the results of the microphysical calculations along the trajectories is shown in Fig. 7 together with the measured backscatter ratio BSR(1064). This allows a direct comparison of simulations and measurements, while the underlying microphyiscal results, such as particle types and number densities, are shown later (see Fig. 9). Model results along trajectories are plotted in the geometry of the flight path (positions are resampled to equal distance from the reference position where flight path and all trajectories intersect).

A comparison of the HRM-based PSC simulation (Fig. 7b) with the measured lidar signal (Fig. 7a) shows that the simulation is in good agreement with the measurement. In particular, the shape of first ice cloud over Scandinavia fits the observation very well, and hence corroborates the HRM mesoscale simulation in combination with the modeling of the ice nucleation. Also the second ice cloud is in general agreement with measurements, although its shape shows a tilt westward with height which is too strong compared to the measurement. Measured and simulated lidar backscatter ratios agree well and deviations are on average less than $25 \%$. We conclude that the mesoscale/microphysical model simulation correctly reproduces the cloud microphysics, in particular the particle types, number densities and sizes. It is emphasized again at this point that the simulation uses the meteorological parameters temperature and pressure from the HRM simulation without any modification, and that the microphysical box model calculates the nucleation of ice and NAT particles from nucleation rates rather than from prescribed values as in previous studies.

Upon closer inspection of measurement and simulation we note again the wrong tilt of the second ice cloud. A part of this tilt is an effect of the deviation between flight path and trajectories, however it is also apparent in the temperature field of the HRM simulation. This tilt is also observed in the main ice cloud, where it causes trajectories to descend too soon compared to the measurement (i.e. ice particles evaporate too soon in the simulation, compare the ice regions with $\operatorname{BSR}(1064)>100$ at $24-25 \mathrm{~km}$ altitude in the measurement and simulation, Figs. 7a,b). Further we note that the HRM-based simulation cannot reproduce the small scale waves (with wavelength $\lesssim 20 \mathrm{~km}$ and amplitude $\lesssim 5 \mathrm{~K}$ ) superimposed on the dominant wave number observed in the lidar data. It is clear that the mesoscale model with a spatial resolution of $\sim 15 \mathrm{~km}$ cannot resolve these waves. Calculations with a manually modified trajectory with these small scale waves superimposed on the HRM trajectory show that these waves can affect the microphysical properties quantitatively, but do not change the qualitative properties of the cloud (calculations shown in the Appendix).

The simulation cannot reproduce the small PSC at $22 \mathrm{~km}$ altitude upstream of the first ice cloud, in Sect. 4.2 identified as STS and NAT, due to two reasons. Firstly, the microphysical model requires ice particles to initiate NAT nucleation, but the HRM simulation temperatures do not reach the ice nucleation temperature upstream of Scandinavia. Secondly, the HRM backtrajectories are slightly further south than the flight path for this section over the Atlantic (see Fig. 6). As will be shown later, a trough of air cold enough to form STS is present in the simulation at the location where the upstream PSC was observed, but its southern edge is just missed by the HRM trajectories.

In contrast to the HRM-based simulation, the ECMWFbased simulation (Fig. 7c) fails to produce both ice clouds. ECMWF analysis temperatures also reach the ice frost point (see Fig. 8a), but not the required supercooling for ice nucleation. An additional cooling of $1-2 \mathrm{~K}$ would lead to an ice PSC in a narrow altitude range around $510 \mathrm{~K}$ (not shown). In the ECMWF-based simulation the STS cloud upstream of the large ice cloud is present, since ECMWF trajectories around the $500 \mathrm{~K}$ isentrope are further north (see Fig. 6) than the 

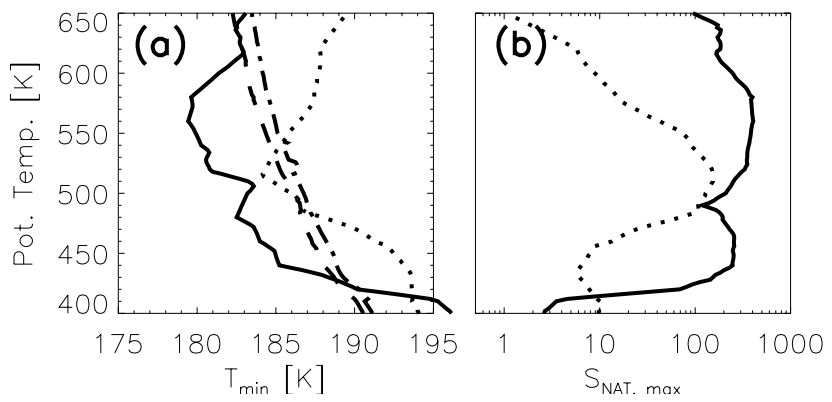

Fig. 8. (a) Minimum temperatures along trajectories from HRM simulation (solid line) and ECMWF analysis (dotted line), and the corresponding ice existence temperatures (dashed line: HRM simulation; dash-dotted line: ECMWF analysis); (b) Maximum saturation ratio of gas phase with respect to NAT in the presence of ice, again along trajectories from HRM simulation (solid line) and ECMWF analysis data (dotted line), calculated with the microphysical box model.

HRM trajectories. Again, trajectories do not reach the ice nucleation temperature further upstream, and consequently the microphysical model fails to produce the observed NAT particles. A hypothesis on the origin of these NAT clouds is beyond the scope of this paper, but we note that these clouds might be a challenge to test hypotheses on NAT nucleation.

Figure 8 shows an overview of the minimum temperatures and the calculated maximum NAT saturation ratios in the presence of ice $\left(\mathrm{S}_{\mathrm{NAT}}\right)$ along the trajectories used for this simulation. As expected from the lower spatial resolution, ECMWF analysis underestimates orographically induced temperature deviations from synoptic scale temperatures. In addition, the underestimation of the wave amplitude yields NAT supersaturations considerably lower than the HRM-based trajectories. The latter yield very high NAT supersaturations of $S_{\mathrm{NAT}} \gtrsim 200$, in agreement with the high supersaturations found in manually constructed trajectories by Luo et al. (2002).

Figure 9a shows the maximum cooling rates found in the HRM trajectories and ECMWF trajectories. The latter cannot reproduce the strong cooling rates found in mountain gravity waves and remain below $10 \mathrm{~K} / \mathrm{h}$. In contrast, the HRM trajectories show maximum cooling rates of 30$50 \mathrm{~K} / \mathrm{h}$, in accordance with manually constructed trajectories (Luo et al., 2002). The maximum cooling rates largely control the STS aerosol. With high cooling rates $\gtrsim 20 \mathrm{~K} / \mathrm{h}$ the $\mathrm{H}_{2} \mathrm{O} / \mathrm{HNO}_{3}$ uptake of the STS droplets cannot keep pace with the decrease in vapor pressure, and the STS aerosol is out of equilibrium with the surrounding gas phase, resulting in extremely high NAT supersaturations with respect to ice as shown in Fig. $8 b$.

Figure $9 \mathrm{~b}$ shows the cooling rates of the HRM-based trajetories at the onset of ice nucleation, which controls the resulting ice particle number density. The largest droplets are to freeze first (due to their volume) and begin to de-

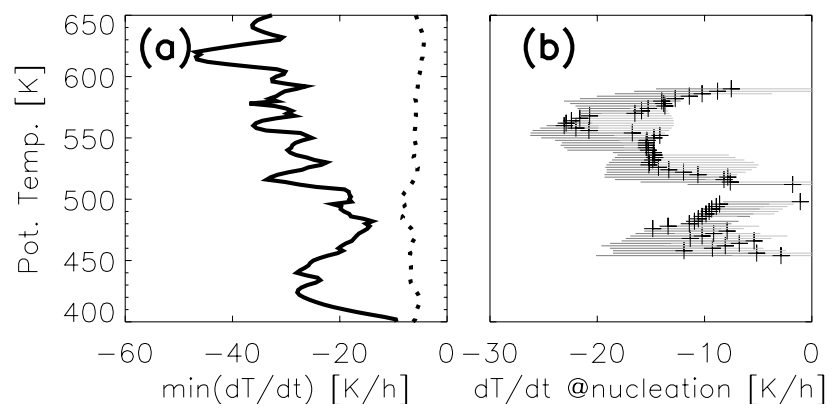

Fig. 9. (a) Maximum cooling rates along trajectories from HRM simulation (black solid line) and ECMWF analysis data (black dotted line). (b) Cooling rate of the HRM trajectories at the onset of ice nucleation (black crosses) and the range of cooling rates within 15 min before (dark gray area) and 3 min after nucleation (light gray area).

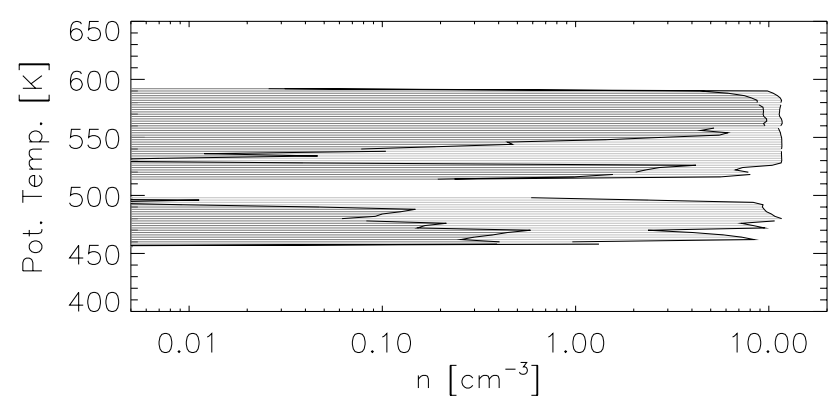

Fig. 10. Solid particle number densities in the PSC simulation of 26 January 2000 (based on HRM simulation). Dark gray shading: NAT number density. Light grey shading: ice number density.

plete the gas phase. As a result, the ice saturation ratio $\left(S_{\text {ice }}=p_{\text {part }} / p_{\text {vapor }}\right)$ decreases. When the saturation ratio falls below the supersaturation required for ice nucleation, further ice nucleation is inhibited. At high cooling rates $\gtrsim 15 \mathrm{~K} / \mathrm{h}$ the decrease in partial pressure is compensated or even overcompensated by a decrease in vapor pressure, such that all droplets freeze (we will refer to this as $100 \%$ ice activation). The majority of cooling rates at onset of nucleation in the HRM trajectories is in the range $10-25 \mathrm{~K} / \mathrm{h}$. Consequently, most trajectories show $\sim 100 \%$ ice activation, despite the fact that nucleation begins at cooling rates significantly lower than the maximum values along the trajectories. In most cases, the cooling rate further decreases during the next 3 min after onset of nucleation, but still remains too high in most cases to restrict resulting ice particle number density. The 3 min timeframe is motivated by the priod of continuous nucleation, which ranges from a few tens of seconds (rapid cooling) to a few minutes (slow cooling).

Figure 10 shows a summary of ice and NAT particle number densities in the simulation. As expected from the cooling rates of the trajectories, the simulation yields almost $100 \%$ ice activation $\left(n_{\text {ice }} \approx 10 \mathrm{~cm}^{-3}\right)$ at all altitudes where ice 
nucleation occurs. This is different for NAT nucleation on ice. The generally lower cooling rates at altitudes of 500$550 \mathrm{~K}$ (see Fig. 9b) allow the liquid aerosol to grow to larger sizes, and supersaturations with respect to NAT remain lower than at higher altitudes. Consequently, the NAT nucleation rate calculated according to Luo et al. (2002) is lower, resulting in $n_{\text {NAT }} \approx 0.1-0.5 \mathrm{~cm}^{-3}$. At higher altitudes the simulations yield NAT number densities of $n_{\mathrm{NAT}} \approx 2-8 \mathrm{~cm}^{-3}$.

In order to quantify the accuracy of the modeled NAT and ice number densities, a detailed analysis of the lidar observations has been performed and is shown in the Appendix. The basic conclusion is that the mesoscale/microphysical model yields results in general agreement with measurements, and that the temperatures and cooling rates of mesoscale models such as HRM suffice to model mountain wave PSCs.

\section{Modeling of PSC evolution, 25-27 January 2000}

In the previous section it was shown that the combined mesoscale/microphysical modeling approach yields results in good agreement with observations. Now we will use this approach to model the 3-dimensional evolution of the PSCs on 25-27 January 2000. Similar to the previous simulation we calculated trajectories from the HRM simulation and used these trajectories as input for the microphysical boxmodel. For this simulation we calculated for each day 200 trajectories on two potential temperature levels, started along a line from $12^{\circ} \mathrm{E} / 59^{\circ} \mathrm{N}$ to $28^{\circ} \mathrm{E} / 72^{\circ} \mathrm{N}$. Based on the altitude level of PSC observations in the lidar data, simulations for 500 and $550 \mathrm{~K}$ potential temperature are shown for 25 and 26 January in Figs. 11 and 12. On 27 January the simulations for 490 and $500 \mathrm{~K}$ are shown. Based on the times of the lidar observations, trajectories were started 15:00 UTC for 25 and 26 January and 11:00 UTC for 27 January.

\subsection{January 2000}

The simulations show STS, NAT and ice clouds both on the $500 \mathrm{~K}$ and $550 \mathrm{~K}$ level. From a comparison with measurements (see Fig. 3), it is apparent that the simulation overestimates temperatures over northern Scandinavia by 1-3 K. The simulations show mainly STS in this region, whereas the measurements show a large ice PSC near Kiruna. The ice PSCs over central Scandianvia are correctly modeled (indicated in Fig. 11 by BSR(1064) > 50, see also Fig. 12). An inspection of NAT number densities in the trajectories that fit best the track of the balloon-borne experiment (near Kiruna) presented by Voigt et al. (2000) shows NAT number densities $n_{\mathrm{NAT}} \approx 0.1 \mathrm{~cm}^{-3}$. This value is in good agreement with the measured $n_{\mathrm{NAT}} \approx 0.1 \mathrm{~cm}^{-3}$ (Voigt et al., 2000). Over central Scandinavia, the simulation yields $n_{\mathrm{NAT}}=0.2-3 \mathrm{~cm}^{-3}$ (see Fig. 12), which is also in good agreement with the results of the analysis of lidar data by Hu et al. (2002), who estimated for this region $n_{\mathrm{NAT}}=0.1-0.5 \mathrm{~cm}^{-3}$.
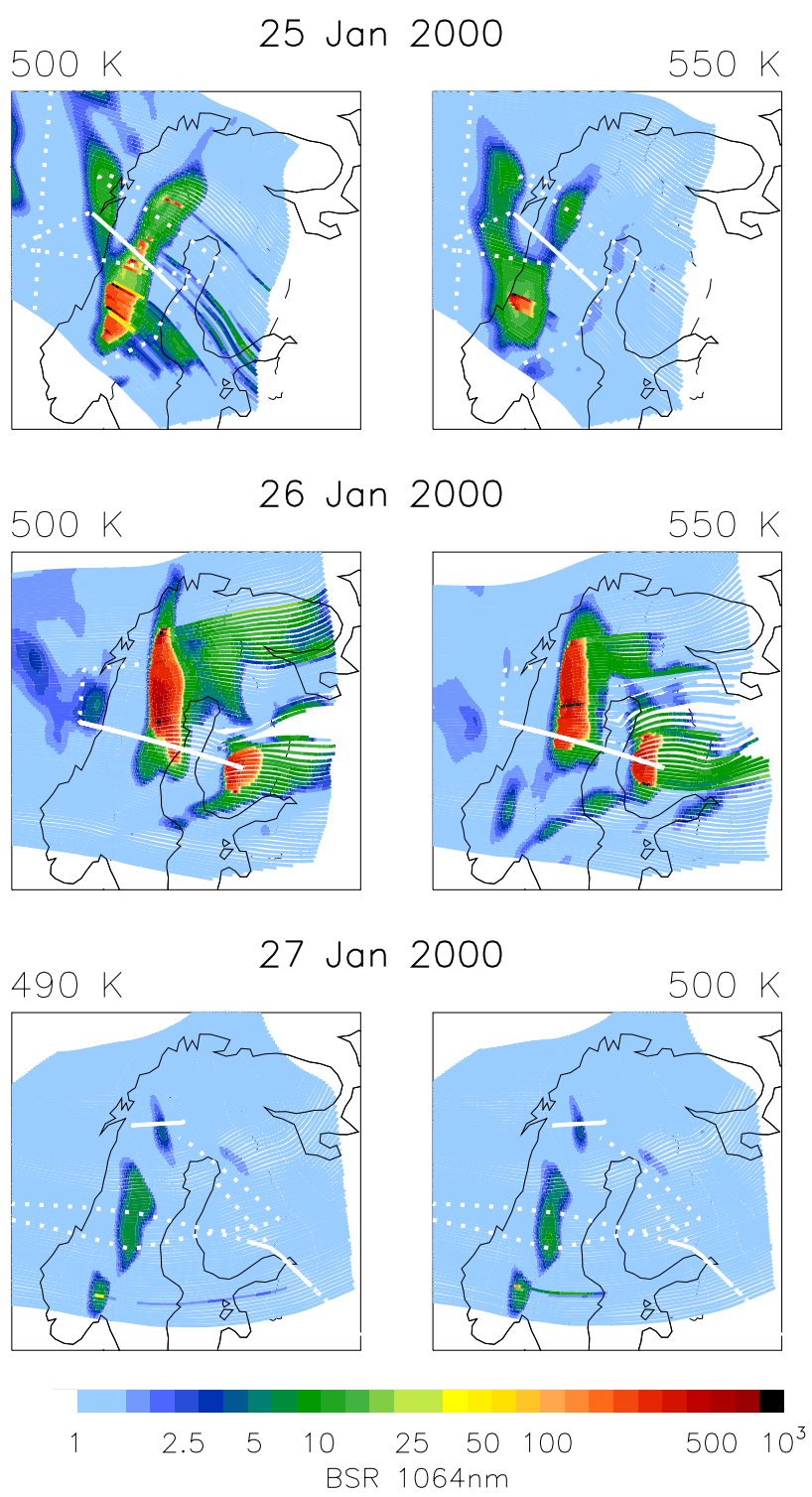

Fig. 11. BSR(1064) calculated from results of combined mesoscale/microphysical modeling on two isentropic levels for 2527 January 2000. Trajectories were started along a straight line from $12^{\circ} / 60^{\circ}$ to $28^{\circ} / 72^{\circ}$ at $15: 00$ UTC of each day (except for 27 January, where trajectories were started at 11:00 UTC). The different trajectory starting time and isentropes of 27 January account for the PSC observation times and altitude range of this day. White solid lines: flight legs discussed in this study (25 January: DC-8; 26 January: Falcon; 27 January: Falcon and DC-8). White dotted lines: entire flight path (25 January: DC-8; 26 January: Falcon; 27 January: DC-8).

\subsection{January}

The simulation of the Falcon measurement (see Sect. 4.2) showed that the simulation and the measurements of this day are in almost prefect agreement with respect to PSC type and spatial dimensions. This is also apparent in these simulations 

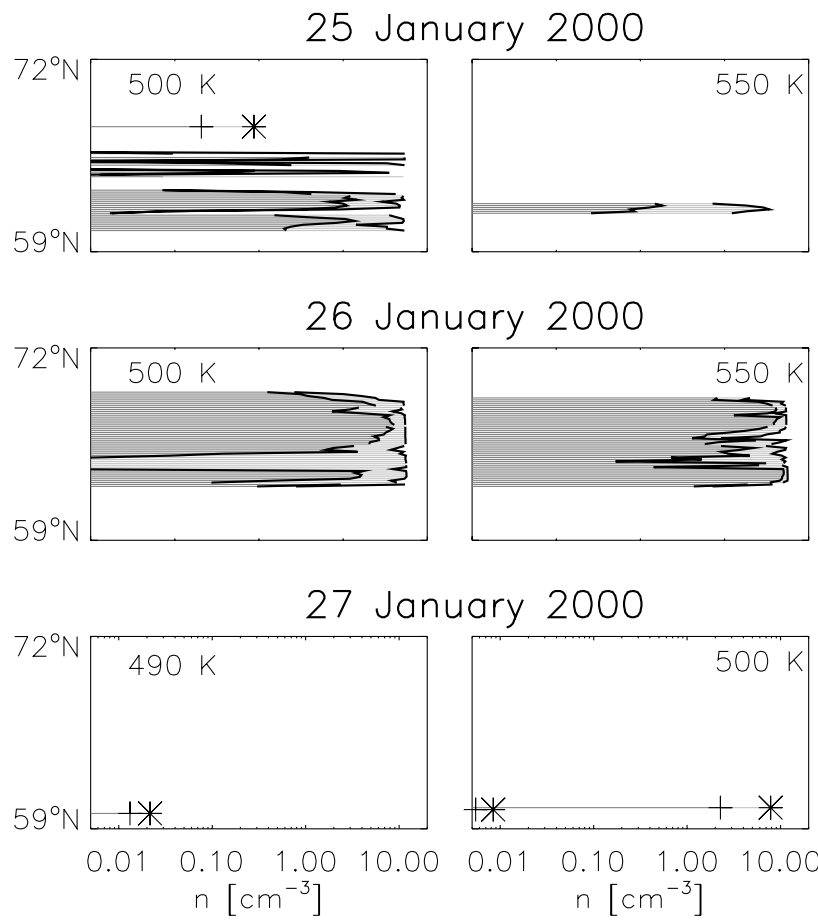

Fig. 12. Solid particle number densities in the simulations. Dark gray: NAT number density. Light grey: ice number density. All panels use the same axes, the values of the individual trajectories are plotted versus the latitude of the starting position. On 27 January only 3 trajectories show ice. To better visualize the data, "+" indicates NAT number density and "*” indicates ice number density where necessary.

on the $500 \mathrm{~K}$ and $550 \mathrm{~K}$ isentropes. These simulations furthermore show that NAT clouds downstream of the northern part of the first ice PSC prevail until the trajectories leave the domain of the simulation (the region with $\operatorname{BSR}(1064) \approx 15$, identification of NAT in the simulation after inspection of the data of the microphysical simulation, Fig. 12). The presence of a region where the NAT PSC evaporates $\sim 200 \mathrm{~km}$ downstream of the ice cloud highlights again the fact that, depending on the temperature history, NAT can also be absent downstream of an ice PSC. It was earlier mentioned that the simulation of the vertical cross-section of 26 January based on HRM data does not show the observed STS cloud upstream of the ice PSC. The simulations shown here support the explanation suggested earlier that the slight displacement of the flight path and the trajectories is responsible for the disagreement. The horizontal simulation reveals a pool of cold air located over the Atlantic, giving rise to STS clouds (BSR $(1064) \approx 3$, identification of STS after inspection of the data of the microphysical simulation). The simulated STS cloud is in agreement with observed STS clouds (see Fig. 3), and ceases to exist at approximately the latitude where the Falcon aircraft turned eastward.

\subsection{January}

The simulation of this day misses the small ice PSC $\sim 50 \mathrm{~km}$ downstream of Kebnekaise $\left(18^{\circ} 33^{\prime} \mathrm{E} / 67^{\circ} 53^{\prime} \mathrm{N}\right.$, elevation $2111 \mathrm{~m}$ ), but correctly predicts the observed STS cloud at the same location. Apparently, the HRM model slightly overestimates temperatures in this region. Considering the limited horizontal resolution $(\sim 15 \mathrm{~km})$ of the HRM model and the smoothed orography, it seems plausible that the model underestimates gravity waves caused by high, but horizontally small orographic features such as Kebnekaise.

The presence of an STS cloud over central Scandinavia in the simulation (with $\operatorname{BSR}(1064) \lesssim 10$ ) is confirmed by the LaRC measurements on board the DC-8 (see Fig. 3). The simulation does not show the observed NAT PSC near Helsinki/St. Petersburg (see Figs. 3 and 5d), but holds a plausible explanation for the cloud. The simulation shows the presence of a small ice cloud over southern Scandinavia (near Oslo), which gives rise to a NAT cloud downstream (the small line in the horizontal simulation with BSR(1064) = $2-10$, identification of NAT after inspection of the data of the microphysical simulation, Fig. 12). In the simulation, temperatures further downstream are slightly too high such that the NAT particles evaporate shortly before the air trajectory intersects with the flight path. We have refrained from lowering the temperatures by $\sim 1 \mathrm{~K}$ which would be required to produce a 'match' with the observed type 1a-enh PSC, to remain in accordance with all other simulations where all meteorological parameters of the NWP models remained unaltered. An inspection of the data of the microphysical simulation (see Fig. 12) shows a number density of the ice cloud near Oslo $n_{\text {ice }}=0.01-8 \mathrm{~cm}^{-3}$ (i.e. also very slow cooling rates at the onset of nucleation). The simulated NAT cloud downstream shows $n_{\mathrm{NAT}}=0.01-2 \mathrm{~cm}^{-3}$ (i.e. a large range of number densities), which is in agreement with our earlier calculations based on the measured lidar data, which concluded $n_{\mathrm{NAT}} \approx 0.3 \mathrm{~cm}^{-3}$ and $r \approx 0.8 \mu \mathrm{m}$.

\section{Conclusions}

We presented a detailed modeling study of orographically induced gravity wave PSCs over Scandinavia on 25-27 January 2000 by means of a combined mesoscale/microphysical model. Extensive observation of this PSC event during the second phase of the SOLVE/THESEO-2000 Arctic campaign provides an excellent data set of ground-based, balloon-borne and aircraft-borne in-situ and remote sensing measurements. We analyzed lidar data of the DLR OLEX system on board the Falcon aircraft and of the NASA LaRC system on board the DC-8. In addition, we compared the model results with data of the $\mathrm{NO}_{\mathrm{y}}$ instrument on board the NASA ER-2 (Northway et al., 2002) and balloon-borne mass spectrometer data (Voigt et al., 2000). 
The model simulations use trajectory calculations based on mesoscale simulations with the High Resolution Model (HRM) as input for our microphysical box model. All microphysical calculations use the meteorological information of the trajectories without modifications (i.e. without "tuning" of the temperature). We calculate a lidar signal from the microphysical simulation with T-Matrix calculations for aspherical particles and Mie calculations for liquid particles. The comparison of simulations and measurements shows:

a The mesoscale HRM simulations of orographically induced gravity waves over Scandinavia are in good agreement with lidar observations. As a general tendency, the wave amplitude appears to be slightly underestimated rather than overestimated, such that the simulations do not always yield ice when observations indicate the presence of ice. However, in general the mesoscale simulation captures minimum temperatures and cooling rates well. Sensitivity studies (not shown) show that the results of the mesoscale modeling are robust, i.e. that for different model setups the results do not critically differ. We conclude from this study that the mesoscale modeling is sufficiently reliable to model the microphysics of mountain wave ice PSCs over Scandinavia, even though it still misses very small ice clouds which may be caused by orographic features that are either not present in the model orography or cause gravity waves which cannot be resolved even with a horizontal resolution of $\sim 15 \mathrm{~km}$.

Simulations with ECMWF analysis data show that the model, as a consequence of its synoptic scope and coarse resolution, severely underestimates lowest temperatures and cooling rates. Consequently, ECMWF data (and data of other NWP models with similar spatial resolution) are only suited for the study of liquid PSCs on a synoptic scale.

b The simulations show that in mountain wave PSC events the ice PSC observations are in agreement with simulations assuming homogeneous ice nucleation and using the parametrization of Koop et al. (2000). The accuracy of the mesoscale trajectory calculations is not sufficient to resolve details of the ice PSCs, but on a statistical basis the simulations yielded both ice number densities and particle sizes within the range of observations. We estimate the accuracy of the modeled particle number densities within a factor 2 for ice particles. A more precise estimation of the accuracy is not (yet) possible due to the uncertainties in the interpretation of the (lidar) data.

c This modeling study assumes NAT nucleation on ice according to the process described by Luo et al. (2002). All observations of NAT in the region of interest could be explained with this process except patches of NAT clouds over the Atlantic, which we have not further analyzed in this study. This study supports the assumption that NAT forms in (mountain wave) ice PSCs, though it does not exclude other nucleation mechanisms. The accuracy of the modeled NAT number density is estimated to be within a factor 10 , the uncertainty again largely caused by uncertainties in the interpretation of the measurements. The importance of combined in-situ and lidar measurements to finally overcome limitations in the lidar data retrieval cannot be overemphasized.

d If NAT nucleation on ice is of importance to the denitrification of the polar stratosphere (e.g. via sedimentation of NAT particles out of high number density NAT clouds as proposed by Fueglistaler et al., 2002a,b; Dhaniyala et al., 2002), then Chemical Transport Models (CTM) using synoptic scale temperature and wind fields miss a key element in the process of ozone destruction. Ice PSCs cannot be simulated realiably with synoptic scale temperature fields, and consequently the formation of NAT particles, their sedimentation and the resulting denitrification is not accurate.

In summary, this study shows that the combined mesoscale/microphysical modeling approach yields results in good agreement with observations and enables the investiagation of the 3-dimensional structure of mountain wave PSCs. The results of this approach are the first of their kind and show a level of detail in the modeling and comparison with measurements not performed before. It is shown that the current understanding of PSC microphysics and mesoscale dynamics modeling suffices to explain the key characteristics of mountain wave PSC events. However, the study also implies that currently available data do not suffice to draw new conclusions about the microphysics of PSCs (despite the excellence of the SOLVE/THESEO-2000 campaign data). It is conceivable that future Arctic campaigns use not only meteorological forecasts, but also microphysical calculations based on mesoscale forecasts to guide mission planning. This approach could contribute to observations that allow to reject or prove suggested microphysical processes in PSCs, and hence to a significant improvement of our understanding of PSC formation.

\section{Appendix: Detailed lidar data retrieval 26 January 2000}

Figure 13 shows the measured color ratio $\mathrm{CR}(532 / 1064)$, scatterplots of the data in the $\delta^{\text {aer }}(532) / \mathrm{BSR}(1064)$ plane (Figs. 13b, c, d) together with color ratios calculated with the T-Matrix method for ice and NAT particles (Figs. 13e, f; the particle shape is a spheroid with aspect ratio 0.5 to 1.5 ).

Four regions of particular interest are indicated in Fig. 13a. Regions "A" and "B" refer to two regions of the ice cloud with a distinct color ratio. Data of region "A" shows a higher 

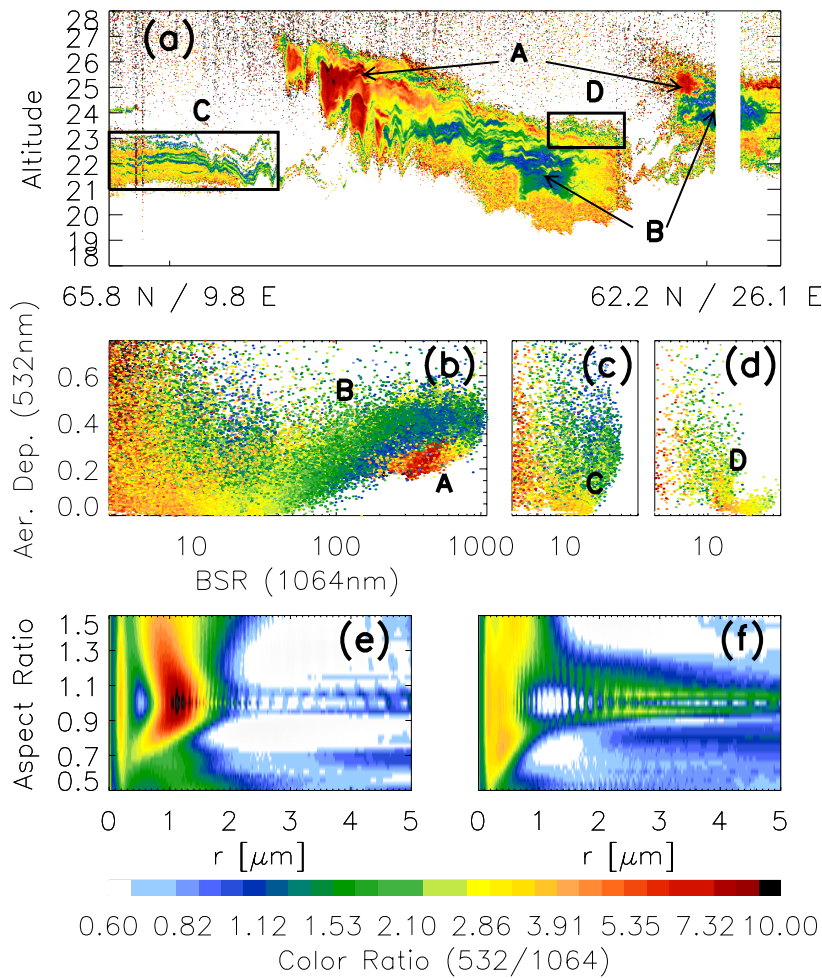

Fig. 13. (a) Color ratio CR(532/1064) of OLEX measurement on 26 January 2000 (leg 3). The regions A-D are discussed in text. (b) Scatterplot of lidar data of 26 January 2000 (leg 3). Note that the high color ratio value region at $\operatorname{BSR}(1064)=200-800$ is partially covered by points with lower color ratios. (c) Scatterplot of lidar data of region C. (d) Scatterplot of lidar data of region D. (e) TMatrix calculation of CR(532/1064) for spheroids, ice. (f) T-Matrix calculation of CR(532/1064) for spheroids, NAT.

color ratio and a tendency towards lower aerosol depolarization (see Fig. 13b) compared to region "B" (note that the plotting in a scatterplot leads to an overplot of a small fraction of data with high color ratio and high aerosol depolarization). Regions "C" and "D" cover areas of interest with respect to the occurrence of NAT particles. Data of these regions cannot be unequivocally identified in the scatterplot due to noise in the depolarization data at $\operatorname{BSR}(1064) \lesssim 5$ (probably caused by an iced window, H. Flenje, pers. comm.).

Ice particles

The observed difference in color ratio in the ice cloud between regions above $\sim 23 \mathrm{~km}$ ("A") and below ("B") indicates that the sizes of the ice particles in the two regions differ. Region "A" shows a high backscatter and a color ratio $\mathrm{CR}(532 / 1064)=5-9$. Based on the T-Matrix calculations shown in Fig. 13e, we estimate ice particle sizes $r=1-1.5 \mu \mathrm{m}$ (with aspect ratio $\sim 0.9$ ) in this region. In thermodynamic equilibrium at $T \approx T_{\text {ice }}-3 \mathrm{~K}$ a particle size of $r \leq 1.5 \mu \mathrm{m}$ requires $n_{\text {ice }} \geq 10 \mathrm{~cm}^{-3}$. This implies that basically the entire background aerosol froze, which in turn requires cooling rates $>10 \mathrm{~K} / \mathrm{h}$ at the onset of ice nucleation (based on sensitivity studies for different cooling rates, calculated with the microphysical box model). The calculated ice number densities in the simulation in this region of $n_{\text {ice }}=10-12 \mathrm{~cm}^{-3}$ (see Fig. 10) agree well with these considerations based on the lidar data.

Region "B" shows a similar BSR(1064) as region "A", but has a significantly lower color ratio $\mathrm{CR}(532 / 1064)<1.5$. An inspection of the T-Matrix calculations (see Fig. 13e) shows that the observations can be explained by ice particles of size $r \gtrsim 1.8 \mu \mathrm{m}$ and aspect ratio 0.9 , with a corresponding particle number density $n_{\text {ice }} \lesssim 5 \mathrm{~cm}^{-3}$. Calculations show that altitude-dependent variations in available water vapor affect ice particle sizes, but cannot be the only reason for the different color ratios of regions " $A$ " and "B". Rather, we consider a different particle shape of ice particles in the two regions a likely cause. Figure $13 \mathrm{e}$ shows that particles with aspect ratio $\sim 0.65$ show moderate color ratios $\mathrm{CR}(532 / 1064) \lesssim 2$ for practically all particle sizes. This is in accordance with the fact that a distinct peak in color ratio, as expected for growing ice particles with aspect ratio $\gtrsim 0.8$, is not observed in region "B". In principle, also very slow cooling rates $(\lesssim 2.5 \mathrm{~K} / \mathrm{h})$ could lead to the observed low color ratios, even for particles with aspect ratio 0.85 . Cooling rates $\lesssim 2.5 \mathrm{~K} / \mathrm{h}$ lead to $n_{\text {ice }} \lesssim 1 \mathrm{~cm}^{-3}$ ice particles, which follow a wide size distribution, such that the distinct peak in color ratio at $r \approx 1 \mu \mathrm{m}$ diminishes. An estimation of cooling rates based on the lidar data of the STS cloud upstream of the ice cloud yields an average cooling rate $\sim 10 \mathrm{~K} / \mathrm{h}$ (in agreement with the HRM simulation, Fig. 8b), which is considerably higher than the required $2.5 \mathrm{~K} / \mathrm{h}$. Even under the assumption of lower cooling rates at the begin of nucleation, an aspect ratio $\sim 0.85$ for ice particles appears unlikely. Minor variations in the cooling rate of $\pm 1 \mathrm{~K} / \mathrm{h}$ (which can be safely expected for the stratosphere) inevitably lead to variations in particle number density that cause significantly higher than observed color ratios. Thus, we consider differing aspect ratios in region " $\mathrm{A}$ " and "B" the most likely hypothesis for the systematic difference in color ratio.

On the reason for a systematic difference in particle shapes of region "A" and "B" we can only speculate. As outlined above, cooling rates are lower upstream of region "B" (though still high enough to freeze most of the background aerosol). Consequently, the ice particles of region "B" nucleated in larger droplets and grew in an environment closer to the thermodynamic equilibrium, which could favour crystal growth along the preferred axes, and hence a more prolate shape.

To conclude this discussion of the ice PSC, we note that the mesoscale HRM simulation cannot help to support or reject any of the hypotheses presented above. On the one hand, the HRM simulation underestimates the cooling rates upstream of region "A", as indicated by the presence of STS upstream of the ice region in the simulation in contrast to 
the observation (see Fig. 7b). On the other hand, the mean cooling rates upstream of region "B" appear realistic from a comparison of the horizontal dimensions of the STS upstream of region "B". Yet, the cooling rates at the location of ice nucleation is still too high (see Fig. 9b) to severly reduce the number of freezing particles (see Fig. 10). The extreme sensitivity of ice nucleation rates on cooling rates would require trajectories with an accuracy in cooling rates within $\pm 0.5 \mathrm{~K} / \mathrm{h}$, which is far beyond from what current NWP models can deliver.

\section{NAT particles}

The lidar classification discussed in Sect. 4.2 shows a substantial fraction of pixels directly downwind of the ice cloud (region "D") classified as "NAT" or "mixed", but the signal is noisy. Here we compare the signal in the two regions " $\mathrm{C}$ " and "D" (Figs. 13c, d). Region "C" is clearly classified as STS, "mix" and a layer of NAT particles. The layer dominated by NAT shows a distinct color ratio $\mathrm{CR}(532 / 1064)=1-2$, whereas the other parts of region "C" show CR(532/1064) ¿ 3.25. A comparison with T-Matrix calculations (Fig. 13f) shows that the observed signal (significant depolarization and color ratio $\mathrm{CR}(532 / 1064)=1-2)$ is in agreement with NAT particles with $r \gtrsim 0.5 \mu \mathrm{m}$. The observed backscatter ratio $\operatorname{BSR}(1064)=5-30$ indicates $n_{\mathrm{NAT}}=0.5-3 \mathrm{~cm}^{-3} \mathrm{NAT}$ particles (with $r=0.5 \mu \mathrm{m}$ ), with a corresponding $\mathrm{HNO}_{3}$ mixing ratio $1-5$ ppbv in the solid phase.

Region "D" shows similar aerosol depolarization as region "C", but a lower backscatter ratio (BSR $(1064)=5-15)$ and color ratios $\mathrm{CR}(532 / 1064)=1.5-3.25$. This indicates that region ' $\mathrm{D}$ ' contains NAT particles with a size $r \lesssim 0.5 \mu \mathrm{m}$ and particle number densities of $n=0.5-10 \mathrm{~cm}^{-3}$, corresponding to $<3$ ppbv $\mathrm{HNO}_{3}$ in the solid phase. This analysis shows that $n=0.5-10 \mathrm{~cm}^{-3}$ NAT particles may well be present downwind of the ice PSC, but the period of time where temperatures are too high for STS but still below $T_{\mathrm{NAT}}$ is too small to cause a clear 1a-enh classification.

Simulation results of a manually optimized trajectory

Figure 14 shows a detailed comparison of microphysical and optical parameters between model calculations along the HRM $550 \mathrm{~K}$ trajectory and a manually modified trajectory (based on the $550 \mathrm{~K}$ HRM trajectory and lidar data interpretation; the white line in Fig. 7a shows the location of the trajectory in the geometry of the lidar data). The figure shows that much of the inconsistency between measured lidar signal and HRM-based simulations can be explained by a few shortcomings in the HRM trajectory. In particular, the spatial wavelength of the main gravity wave over Scandinavia is underestimated in the HRM simulation, and temperatures of the manual trajectory remain longer below $T_{\text {ice }}$ (see Fig. 14a), and hence ice particles prevail.
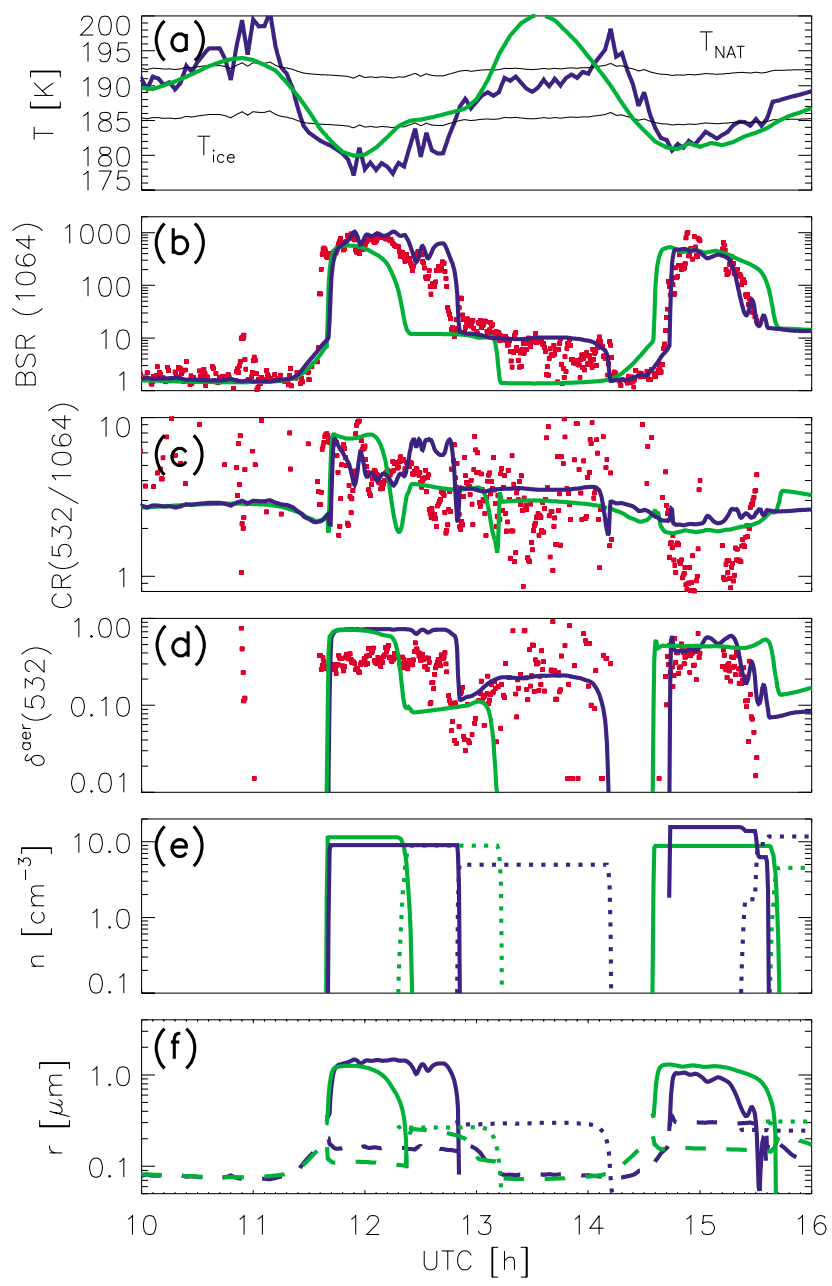

Fig. 14. Comparison of microphysical simulations along HRM $550 \mathrm{~K}$ trajectory, manually modified HRM trajectory $(550 \mathrm{~K})$, and lidar measurement along the modified trajectory. (a) Temperature of HRM trajectory (green) and modified trajectory (blue); (b) BSR(1064) along trajectories. Red dots: OLEX measurement along manually adjusted trajectory; blue line: calculated lidar signal along modified trajectory; green line: calculated lidar signal along HRM trajectory. The lidar backscatter calculations use spheroids with aspect ratio 0.85 for ice and 0.75 for NAT. (c) Lidar color ratio (532 $\mathrm{nm} / 1064 \mathrm{~nm}$, colors as in (b). Calculations for second ice cloud use aspect ratio 0.7 for ice particles. (d) Aerosol depolarization (532 $\mathrm{nm}$ ), colors as in (b). Calculations for second ice cloud use aspect ratio 0.7 for ice particles. (e) Number densities of ice (solid) and NAT (dotted), colors as in (b). (f) Particle mode radius of ice (solid), NAT (dotted) and liquid (dashed), colors as in (b).

The cooling rates of the manual trajectory were adjusted in the area where ice nucleation occurs, such that the observed and modeled lidar backscatter agree. For this trajectory, $n_{\text {ice }} \approx 10 \mathrm{~cm}^{-3}$ yield an inferred lidar signal in best agreement with the observations. The temperature variations due to the small scale waves (not resolved in the HRM simulation) lead to a variation of the simulated lidar backscatter 
in good agreement with the observed variation of BSR(1064) in the ice cloud. While the simulated backscatter ratio at $1064 \mathrm{~nm}$ is in good agreement with observations (independently of aspect ratio), it is more difficult to correctly model CR(532/1064) and aerosol depolarization. Figures $14 \mathrm{~b}$ and $\mathrm{c}$ show the observed and simulated color ratios and aerosol depolarizations. For the second ice cloud, which has a lidar signal similar to the earlier discussed region "B", we used an ice particle aspect ratio 0.7 , in accordance with our earlier considerations (all other calculations used an aspect ratio 0.85 for ice particles). The calculation with aspect ratio 0.85 for ice particles is in good agreement with measured color ratios in the first ice cloud, but overestimates aerosol depolarization. In contrast, the calculation with aspect ratio 0.7 for the second ice cloud is in good agreement with observed aerosol depolarization, but overestimates color ratios.

As a result of the rapid cooling, the model yields downwind of the first ice PSC (at $\sim 13-14: 00$ UTC) $n_{\mathrm{NAT}} \approx$ $10 \mathrm{~cm}^{-3}$ NAT particles (i.e. on most ice particles a NAT particle nucleated). Backscatter, color ratio and depolarization of the sections where NAT particles prevail are in general agreement with the observations. Deviations may be explained by the fact that it is difficult to follow the air flow in the lidar image, and consequently the manual trajectory is not perfectly quasi-Lagrangian (note the increased scatter in the lidar data around 13:30-14:00 UTC). Downwind of the second PSC the simulation yields $n_{\mathrm{NAT}}=5-10 \mathrm{~cm}^{-3}$ NAT particles (again almost $100 \%$ activation).

In summary, the manually modified trajectory improves the agreement between simulation and measurement, but does not fundamentally change the results obtained with the HRM trajectories. The original HRM trajectory may not be able to resolve details, but yields particle number densities and sizes very similar (within a factor 2) to the manually optimized trajectory. From this detailed analysis we conclude that the combined mesoscale/microphysical modeling approach yields results in general agreement with measurements, and that temperatures and cooling rates of mesoscale models such as HRM suffice to model mountain wave PSCs.

Acknowledgements. SF and SB have been supported through the EC-project THESEO-2000/EuroSOLVE (under contract BBW 99.0218-2, EVK2-CT-1999-00047) and through an ETHZ-internal research project. BL has been supported through the EC-project MapScore. We thank D. Lüthi for his help with the setup of the HRM model. We thank A. Dörnbrack, C. Schiller, T. Deshler, and C. Voigt for fruitful discussions.

\section{References}

Biele, J., Tsias, A., Luo, B. P., Carslaw, K. S., Neuber, R., Beyerle, G., and Peter, Th.: Nonequilibrium coexistence of solid and liquid particles in Arctic stratospheric clouds, J. Geophys. Res., 106, 22991-23007, 2001

Browell, E. V., Butler, C. F., Ismail, S., Robinette, P. A., Carter, A. F., Higdon, N. S., Toon, O. B., Schoeberl, M. R., and Tuck,
A. F.: Airborne Lidar Observations In The Wintertime Arctic Stratosphere: Polar Stratospheric Clouds, Geophys. Res. Lett., 17, 385-388, 1990.

Carslaw, K. S., Luo, B. P., Clegg, S. L., Peter, Th., Brimblecombe, P., and Crutzen, P. J.: Stratospheric aerosol growth and $\mathrm{HNO}_{3}$ gas phase depletion from coupled $\mathrm{HNO}_{3}$ and water uptake by liquid particles, Geophys. Res. Lett., 21, 2479-2482, 1994.

Carslaw, K. S., Wirth, M., Tsias, A., Luo, B. P., Dörnbrack, A., Leutbecher, M., Volkert, H., Renger, W., Bacmeister, J. T., and Peter, Th.: Particle microphysics and chemistry in remotely observed mountain polar stratospheric clouds, J. Geophys. Res., 103, 5785-5796, 1998a.

Carslaw, K. S., Wirth, M., Tsias, A., Luo, B. P., Dörnbrack, A., Leutbecher, M., Volkert, H., Renger, W., Bacmeister, J. T., Reimer, E., and Peter, Th.: Increased stratospheric ozone depletion due to mountain-induced atmospheric waves, Nature, 391, 675-678, 1998b.

Dhaniyala, S., McKinney, K. A., and Wennberg, P. O.: Lee-wave clouds and denitrification of the polar stratosphere, Geophys. Res. Lett., 29, 9, 1322, doi:10.1029/2001GL013900, 2002.

Dörnbrack, A., Leutbecher, M., Kivi, R., and Kyrö, E.: Mountain wave-induced record low stratospheric temperatures above northern Scandinavia, Tellus, 51A, 951-963, 1999.

Dörnbrack, A., Leutbecher, M., Reichardt, J., Behrendt, A., Müller, K.-P., and Baumgarten, G.: Relevance of mountain wave cooling for the formation of polar stratospheric clouds over Scandinavia: Mesoscale dynamics and observations for January 1997, J. Geophys. Res., 106, 1569-1581, 2001.

Dörnbrack, A., Birner, Th., Fix, A., Flentje, H., Meister, A., Schmid, H., Browell, E. V., Mahoney, M. J.: Evidence for inertia-gravity waves forming polar stratospheric clouds over Scandinavia, J. Geophys. Res., 7, D20, 8287 , doi:10.1029/2001JD000452, 2002.

Fahey, D.W., Gao, R. S., Carslaw, K. S., Kettleborough, J., Popp, P. J., Northway, M. J., Holecek, J. C., Ciciora, S. C., McLaughlin, R. J., Baumgardner, D. G., Gandrud, B., Wennberg, P. O., Dhaniyala, S., McKinney, K. A., Peter, Th., Salawitch, R. J., Bui, T. P., Elkins, J. W., Webster, C. R., Atlas, E. L., Jost, H., Wilson, J. C., Herman, R. L., and Kleinböhl, A.: The Detection of Large $\mathrm{HNO}_{3}$-Containing Particles in the Winter Arctic Stratosphere, Science, 291, 1026-1031, 2001.

Flentje, H., Kiemle, C, Weiss, V., Wirth, M., and Renger, W.: The 3 wavelengths lidar ALEX and other instrumentation onboard the Falcon, ESTEC, Noordwijk, 39-41, ESA WPP-170, ISSN 10226656, 1999.

Fueglistaler, S., Luo, B. P., Voigt, C., Carslaw, K., and Peter, Th.: NAT-rock Formation By Mother Clouds: A Microphysical Model Study, Atmos. Chem. Phys., 2, 93-98, 2002a.

Fueglistaler, S., Luo, B. P., Buss, S., Wernli, H., Voigt, C., Müller, M., Neuber, R., Hostetler, C. A., Poole, L. R., Flentje, H., Fahey, D. W., Northway, M. J., and Peter, Th.: Large NAT particle Formation By Mother Clouds: Analysis of SOLVE/THESE 2000 Observations, Geophys. Res. Lett., 29, 12, 1610, doi:10.1029/2001GL014548, 2002b.

Gao, R. S., Richard, E. C., Popp, P. J., Toon, G. C., Hurst, D. F., Newman, P. A., Holecek, J. C., Northway, M. J., Fahey, D. W., Danilin, M. Y., Sen, B., Aikin, K., Romashkin, P. A., Elkins, J. W., Webster, C. R., Schauffler, S. M., Greenblatt, J. B., McElroy, C. T., Lait, L. R., Bui, T. P., and Baumgardner, D., Obser- 
vational evidence for the role of denitrification in Arctic stratospheric ozone loss, Geophys. Res. Lett., 28, 2879-2882, 2001.

Hanson, D. and Mauersberger, K.: Laboratory studies of nitric acid trihydrate: implications for the south polar stratosphere, Geophys. Res. Lett., 15, 8, 855-858, 1998.

Hoepfner, M., Blumenstock, Th., Hase, F., Zimmermann, A., Flentje, H., Fueglistaler, S.: Mountain polar stratospheric cloud measurements by ground based FTIR solar absorption spectroscopy, Geophys. Res. Lett., 28, 2189-2192, 2001.

Hu, R.M., Carslaw, K. S., Hostetler, C., Poole, L. R., Luo, B. P., Peter, Th., Fueglistaler, S., McGee, Th. J., and Burris, J. F.: The microphysiscal properties of wave PSCs retrieved from lidar measurements during SOLVE/THESEO 2000, J. Geophys. Res., 107, D20, 8294, doi:10.1029/2001JD001125, 2002.

Kleinböhl, A., Bremer, H., von König, M., Küllmann, H., Künzi, K. F., Goede, A. P. H., Browell, E. V., Grant, W. B., Toon, G. C., Blumenstock, T., Galle, B., Sinnhuber, B.-M., and Davies, S.: Vortexwide Denitrification of the Arctic Polar Stratosphere in Winter 1999/2000 determined by Remote Observation, J. Geophys. Res., 108, D05, 8305, doi:10.1029/2001JD001042, 2003.

Koop, Th., Luo, B. P., Tsias, A., and Peter, Th.: Water activity as the determinant for homogeneous ice nucleation in aqueous solutions, Nature, 406, 611-614, 2000.

Krieger U. K., Mossinger, J. C., Luo, B. P., Weers, U., and Peter, Th.: The measurement on the refractive indices of $\mathrm{H}_{2} \mathrm{SO}_{4}$ $\mathrm{HNO}_{3}-\mathrm{H}_{2} \mathrm{O}$ solutions to stratospheric temperatures, Appl. Opt., 39, 3691-3703, 2000.

Luo, B. P., Carslaw, K. S., Peter, Th., and Clegg, S. L.: Vapour pressures of $\mathrm{H}_{2} \mathrm{SO}_{4} / \mathrm{HNO}_{3} / \mathrm{HCl} / \mathrm{HBr} / \mathrm{H}_{2} \mathrm{O}$ solutions to low stratospheric temperatures, Geophys. Res. Lett., 22, 247-250, 1995.

Luo, B. P., Voigt, C., Fueglistaler, S., and Peter, Th.: Extreme NAT supersaturations in mountain wave ice PSCs - a clue to NAT formation, J. Geophys. Res., submitted, 2002.

Lüthi, D., Cress, A., Davies, H. C., Frei, C., and Schär, C.: Interannual variability and regional climate simulations, Theor. Appl. Climatol., 53, 185-209, 1996.

Majewski, D.: The Europa-Model of the DWD, ECMWF Seminar on numerical methods in Atmospheric Science, 2, 147-191, 1991.

Marti, J. and Mauersberger, K.: Laboratory simulations of PSC particle formation, Geophys. Res. Lett., 20, 359-362, 1993.

McElroy, M. B., Salawitch, R. J., Wofsy, S. C., and Logan, J. A.: Reductions of Antarctic ozone due to synergistic interactions of chlorine and bromine, Nature, 321, 759-762, 1986.

Meilinger, S. K., Koop, T., Luo, B. P., Huthwelker, Th., Carslaw, K. S., Crutzen, P. J., and Peter, Th.: Size-dependent stratospheric droplet composition in lee wave temperature fluctuatuations and their potential role in PSC freezing Geophys. Res. Lett., 22, 3031-3034, 1995.

Middlebrook, A. M., Berland, B. S., George, S. M., Tolbert, M. A., and Toon, O. B.: Real refractive indices of infrared-characterized nitric-acid/ice films: Implications for optical measurements of polar stratospheric clouds, J. Geophys. Res., 99, 22 655-22 666, 1994.

Mishchenko, M. I.: Light scattering by randomly oriented axially symmetric particles, J. Opt. Soc. Am., 8, 871-882, 1991.

Molina, L. T. and Molina, M. J.: Production of $\mathrm{Cl} 2 \mathrm{O} 2$ from the selfreaction of the $\mathrm{ClO}$ radical, J. Phys. Chem, 91, 433-436, 1987.
Northway, M. J., Gao, R. S., Popp, P. J., Holecek, J. C., Fahey, D. W., Carslaw, K. S., Tolbert, M. A., Lait, L. R., Mahoney, M. J., Herman, R. L., Toon, G. C., and Bui, T. P.: An analysis of large $\mathrm{HNO}_{3}$-containing particles sampled in the Arctic stratosphere during the winter of 1999-2000, J. Geophys. Res., 107, D20, 8298, doi:10.1029/2001JD001079, 2002.

Pitzer, K. S.: Activity coefficients in electrolyte solutions, CRC Press, 2edt, ISBN 0-8493-5415-3, 1991.

Schiller, C., Bauer, R., Cairo, F., Deshler, T., Dörnbrack, A., Elkins, J., Engel, A., Flentje, H., Larsen, N., Levin, I., Müller, M., Oltmans, S., Ovarlez, H., Ovarlez, J., Schreiner, J., Stroh, F., Voigt, C., and Vömel, H.: Dehydration in the Arctic stratosphere during the THESEO 2000/SOLVE campaigns, J. Geophys. Res., 7, D20, 8293, doi:10.1029/2001JD000463, 2002.

Solomon, S., Garcia, R. R., Rowland, F. S., and Wuebles, D. J.: On the depletion of Antarctic ozone, Nature, 321, 755-758, 1986.

Tabazadeh, A., Santee, M. L., Danilin, M. Y., Pumphrey, H. C., Newman, P. A., Hamill, P. J., and Mergenthaler, J. L.: Quantifying Denitrification and its Effect on Ozone Recovery, Science, 288, 1407-1411, 2000.

Tolbert, M. A., Rossi, M. J., Malhotra, R., and Golden, D. M.: Reaction of Chlorine Nitrate with Hydrogen-Chloride and Water at Antarctic Stratospheric Temperatures, Science, 238, 1258-1260, 1987.

Toon, O. B., Browell, E. V., Kinne S., and Jordan, J.: An Analysis of Lidar Observations of Polar Stratospheric Clouds, Geophys. Res. Lett., 17, 393-396, 1990.

Toon, O. B., Tolbert, M. A., Koehler, B. G., Middlebrook, A. M., and Jordan, J.: Infrared optical constants of $\mathrm{H}_{2} \mathrm{O}$ ice, amorphous nitric acid solutions, and nitric acid hydrates, J. Geophys. Res., 99, 25 631-25 654, 1994.

Tsias, A., Wirth, M., Carslaw, K. S., Biele, J., Mehrtens, H., Reichardt, J., Wedekind, C., Weiss, V., Renger, W., Neuber, R., von Zahn, U., Stein, B., Santacesaria, V., Stefanutti, L., Fierli, F., Bacmeister, J., and Peter, Th.: Aircraft lidar observation of an enhanced type Ia polar stratospheric cloud during APE-POLECAT, J. Geophys. Res., 104, 23 961-23 969, 1999.

Voigt, C., Schreiner, J., Kohlmann, A., Zink, P., Mauersberger, K., Larsen, N., Deshler, T., Kröger, C., Rosen, J., Adriani, A., Cairo, F., Di Donfrancesco, G., Viterbini, M., Ovarlez, J., Ovarlez, H., David, C., Dörnbrack, A.: Nitric Acid Trihydrate (NAT) in Polar Stratospheric Clouds, Science, 290, 1756-1758, 2000.

Waibel, A. E., Peter, Th., Carslaw, K. S., Oelhaf, H., Wetzel, G., Crutzen, P. J., Pöschl, U., Reimer, E., and Fischer, H.: Arctic ozone loss due to denitrification, Science, 283, 2064-2069, 1999.

WMO: Scientific Assessment of Ozone Depletion: 1998, Rep. 44 World Meteorological Organization, Geneva, Switzerland, 1999.

Wernli, H. and Davies, H. C.: A Lagrangian-based analysis of extratropical cyclones. I: The method and some applications, Q. J. R. Meteorol. Soc., 123, 467-489, 1997.

Wirth, M., Tsias, A., Dörnbrack, A., Weiss, V., Carslaw, K. S., Leutbecher, M., Renger, W., Volkert, H., and Peter, Th.: Modelguided Lagrangian observation and simulation of mountain polar stratospheric clouds, J. Geophys. Res., 104, 23 971-23 981, 1999.

Zondlo, M. A., Hudson, P. K., Prenni, A. J., and Tolbert, M. J.: Chemistry and Microphysics of Polar Stratospheric Clouds and Cirrus Clouds, Annu. Rev. Phys. Chem., 51, 473-499, 2000. 